Jarosław Strzałkowski, Pawel Sikora, Sang-Yeop Chung, Mohamed Abd Elrahman

\title{
Thermal performance of building envelopes with structural layers of the same density: Lightweight aggregate concrete versus foamed concrete
}

Journal article | Accepted manuscript (Postprint)

This version is available at https://doi.org/10.14279/depositonce-11686

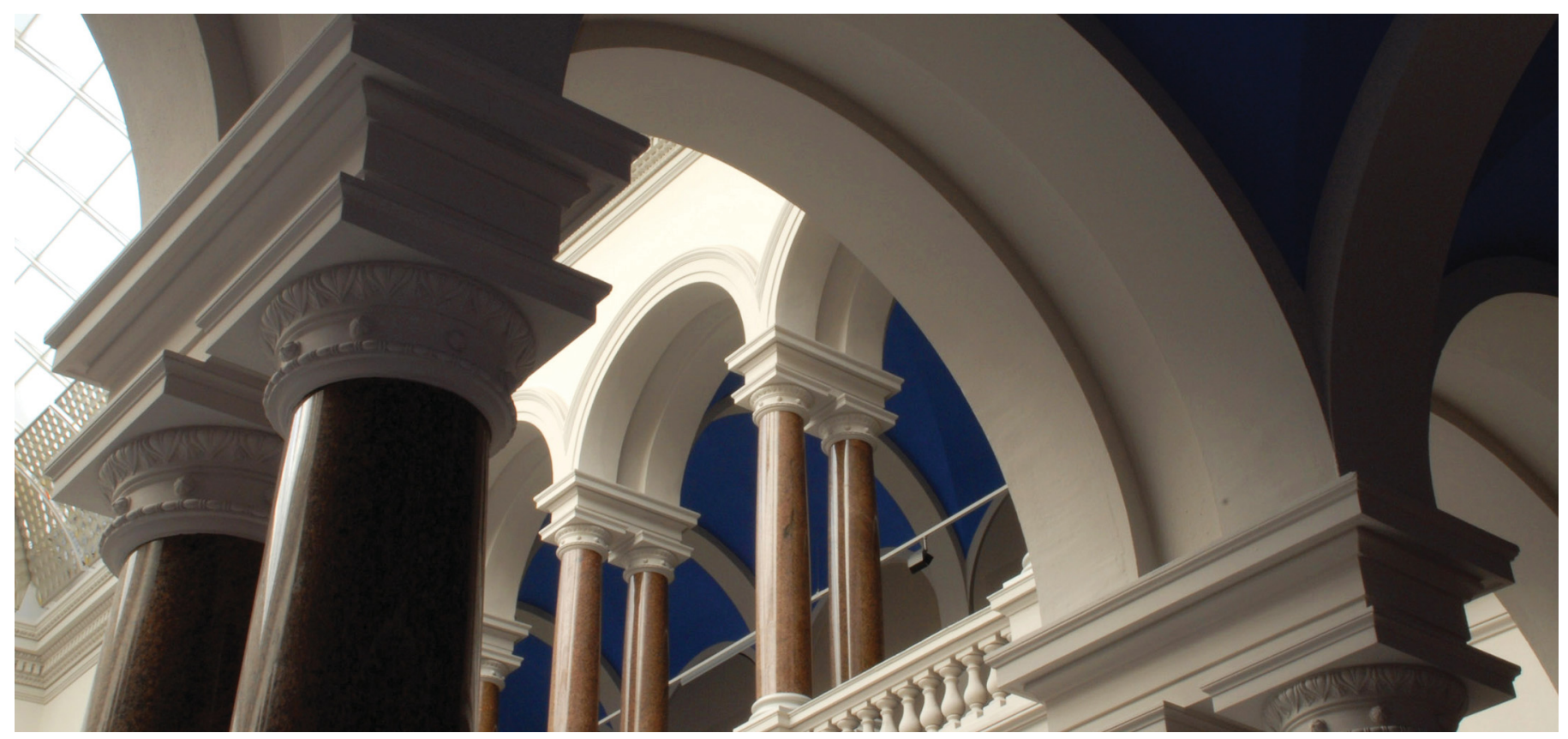

Strzałkowski, J., Sikora, P., Chung, S.-Y., \& Abd Elrahman, M. (2021). Thermal performance of building envelopes with structural layers of the same density: Lightweight aggregate concrete versus foamed concrete. Building and Environment, 196, 107799. https://doi.org/10.1016/j.buildenv.2021.107799 
Accepted manuscript of: Strzałkowski, J., Sikora, P., Chung, S.-Y., Abd Elrahman, M. (2021). Thermal performance of building envelopes with structural layers of the same density: Lightweight aggregate concrete versus foamed concrete. Building and Environment, 196, 107799.

https://doi.org/10.1016/j.buildenv.2021.107799

This manuscript version is made available under the CC-BY-NC-ND 4.0 license http://creativecommons.org/licenses/by-nc-nd/4.0/

\title{
Thermal performance of building envelopes with structural layers of the same density: Lightweight aggregate concrete versus foamed concrete
}

\author{
Jarosław Strzałkowski ${ }^{1}$, Pawel Sikora ${ }^{1,2, *}$, Sang-Yeop Chung ${ }^{3}$, Mohamed Abd Elrahman ${ }^{4}$ \\ ${ }^{1}$ Faculty of Civil and Environmental Engineering, West Pomeranian University of Technology Szczecin, Poland \\ ${ }^{2}$ Building Materials and Construction Chemistry, Technische Universität Berlin, Germany \\ ${ }^{3}$ Department of Civil and Environmental Engineering, Sejong University, South Korea \\ ${ }^{4}$ Structural Engineering Department, Mansoura University, Mansoura, Egypt
}

\begin{abstract}
This study presents a comparative analysis of the effects of lightweight aggregate concrete (LWAC) and foamed concrete (FC), with dry densities of 500,750 and $1000 \mathrm{~kg} / \mathrm{m}^{3}$, on the thermal performance of a typical multi-family (residential) building. Typical two-layer walls consisting of an essential layer (LWAC or FC), with an insulating layer of foamed polystyrene were evaluated. To ensure fixed $U$ values for all variants tested, the thicknesses of the support layers were adjusted accordingly, in such a way that in each variant the load-bearing layer had the same value of the thermal resistance, thus ensuring the same thermal transmittance value for the entire wall. Calculations were made for four different climate zones, making it possible to determine the impact of each variant used, in different climatic conditions. For a hot climate, the data for Cairo (Egypt) was used. A moderate, warm climate was represented by Vienna (Austria), a moderate cold climate by Kołobrzeg (Poland) and a cold climate by Tromsoe (Norway). Significant correlations between the type/density of concrete and climate zones were established. The study shows that, despite comparable densities and thermal conductivity values between LWAC and FC, their specific heat and thus dynamic thermal properties are different. Study provides valuable guidelines and knowledge on choice between proper lightweight concrete type depending on the climate zone. Meaningful conclusions were drawn, showing that the pursue for developing the material with "the lowest" thermal conductivity itself is not the key factor to develop a residential building with satisfactory thermal comfort.
\end{abstract}

Keywords: lightweight concrete; ultra-lightweight concrete; lightweight aggregate concrete; foamed concrete; thermal performance; building envelopes

\section{Corresponding author:}

Pawel Sikora - Building Materials and Construction Chemistry, Technische Universität Berlin, Germany; Faculty of Civil and Environmental Engineering, West Pomeranian University of Technology Szczecin, Poland; pawel.sikora@ zut.edu.pl 


\section{Introduction}

Concrete is the most popular building material used in engineering structures. Compared to other building materials, normal-weight concrete has a wide range of superior properties, such as good mechanical properties, low sorptivity and high durability. In terms of material properties, the thermal performance of concrete is not good enough to use it solely as a building envelope. To reduce its thermal conductivity, other insulation materials needs to be taken into consideration when designing concrete elements. To satisfy the European Energy Efficiency Directive for climate neutrality of building stock by the year 2050, work is actively being carried out to improve the thermal insulation of building envelopes, along with attempts to decrease the total energy used for heating [1]. Such challenges are of high importance, as in a traditional building heat loss system, $70 \%$ of the loss is due to the enveloping structure [2]. This problem is not only significant in countries with cold climates, but also in those located in warm climate zones, where a substantial amount of energy is used for cooling [3-6]. There is, therefore, a strong interest in developing modern building materials to tackle these environmental challenges.

One type of construction material known for its favorable thermal properties is lightweight concrete (LWC), which has a dry density in the range of $800-2000 \mathrm{~kg} / \mathrm{m}^{3}$, according to EN $206-1$. The concrete below this range is considered to be a nonstructural material and is called ultra-lightweight (ULWC) or infra-lightweight concrete [7]. Lightweight concrete can be classified into two main categories: namely, lightweight aggregate concrete (LWAC) and foamed concrete (FC). The former is produced by incorporating lightweight aggregates in a mixture while the latter is a cellular concrete containing large numbers of pores produced by foaming agents. Although, the production technology of modern LWC is well-known for more than a century, this technology has experienced a significant boom in the last two decades. This is attributed to the development of inter alia: high-strength artificial aggregates, new admixtures and additives, advanced measuring techniques as well as substantial improvement of the production methods (e.g. high-shear mixers). These enable to produce advanced lightweight cementitious composites with remarkably improved durability and mechanical properties which allow, despite extremely low density, to use them for structural applications. 
The use of such materials in the construction of engineering structures has manifold benefits: the use of LWC in multi-story buildings can decrease the dead weight of a building, as well as providing significant cost saving related to work time. It has beneficial effects on improving seismic structural response, provides longer spans, improves fire and acoustic resistance, as well as lowering reinforcement ratios and foundation materials [8]. When used in prefabricated elements, it decreases transportation costs. Since it exhibits significantly lower thermal conductivity than normal-weight concrete, it can play a substantial role in decreasing the energy consumption required for heating and cooling [8]. Pan et al. [9] have reported that the incorporation of lightweight concrete blocks as partition walls, leads to a decrease in the direct cost of an apartment by about $8.2 \%-13.9 \%$, as compared to one built with conventional partitions. Furthermore, additional factors, such as transportation costs, enlarged net room area or project duration, are of significance. Kurpińska et al. [10] have performed a comparative study on the production of the prefabricated elements of ordinary and lightweight concrete walls in residential construction, showing that the incorporation of LWAC during the production process can increase the initial costs of a construction process, but on the other hand its use leads to a decrease in construction time and transport costs. Muda et al. [11] have reported that the use of fiber-reinforced structural LWAC in high-rise residential buildings, as compared to the use of conventional concrete and sand-cement brick and clay brick walls, results in energy savings between $3.2 \%$ and $14.8 \%$, across various climatic regions. Moreover, such material can be used without additional insulation in hot-humid tropical and temperate Mediterranean climates. Liu et al. [12] have reported that a properly designed foamed concrete mixture composition noticeably increases the energy savings in a building. The evaluation of a typical, large office building model has shown that in both cold and warm climates in parts of the USA, the use of FC can reduce cooling energy consumption, as all as saving cooling water usage [12].

It is widely agreed that concrete density has a major influence on the thermal conductivity of LWC. In contrast, a higher volume of pores within it results in deterioration of mechanical performance and the durability of related properties. Therefore, there is significant interest in research related to the production of LWC with satisfactory density, mechanical and thermal properties [2], [6], [8], [13], [14]. Among the thermal properties, thermal conductivity is not the only representative property that can 
classify a material as being suitable for insulation. Thermal capacity and thermal mass should also be taken into account when designing a building envelope.

The potential of using ULWC in building envelopes and its performance in relation to LWC has been extensively evaluated by Roberz et al. [15]. The authors have reported that, despite the relatively low density of ULWC (ca. $800 \mathrm{~kg} / \mathrm{m}^{3}$ ), an extremely high thickness would be necessary to apply solely this material in envelope construction in colder climates (Amsterdam, the Netherlands). Robati et al. [16] have evaluated the effects of ULWC used in floor designs, on the energy performance of a typical office building in Australian conditions. The research has revealed that structures with a higher thermal mass, could moderate fluctuations between inside and outside air temperatures. In other words, buildings with a higher concrete mass (thermal mass) stored more heat, which then reduced the peak indoor air temperatures. Moreover, it was found that slab structures produced with ULWC resulted in indoor temperatures that were more sensitive to fluctuations in external air temperatures. Thus, such buildings required more energy to achieve the desired indoor temperature range, as compared to elements built from conventional concrete. Similarly, Kumar et al. [10] have reported that lightweight thermal mass materials have poor dynamic characters (time lag and decrement factor), which should be considered when designing residential buildings. Besides, lightweight construction materials have higher embodied energy than conventional materials.

As such, there is still no agreement between researchers as to whether LWC and ULWC are suitable materials for use in the production of building envelopes. Moreover, more study is required to understand which type of LWC, i.e. lightweight aggregate concrete or foamed concrete, is more favorable for this purpose. For instance, while LWAC is more expensive than FC due to the cost of lightweight aggregates, its compressive strength-to-density ratio is much higher than that of FC. In addition, $\mathrm{LWAC}$ is more durable than $\mathrm{FC}$, though its production requires much more energy than the production of FC. Finally, both materials can be recycled easily, thus making them much more sustainable than conventional concrete.

Based on the above-mentioned studies, it can be concluded that whilst there is a certain amount of knowledge regarding the role of foamed concrete and LWCs, the literature is limited to only one type 
of concrete density or only to selected densities. The novelty of the manuscript is that it presents for the first time a comparative study on thermal performances of lightweight and ultra-lightweight building envelopes produced with LWAC and FC with the same density levels. All concrete mixtures were developed by the authors, and the simulations are based on the experimental data. For this purpose, LWAC and FC mixtures, with initial dry densities of 500, 750, and $1000 \mathrm{~kg} / \mathrm{m}^{3}$, were produced and evaluated. The concretes used in this study covered the range of both ultra-lightweight concretes (500 and $\left.750 \mathrm{~kg} / \mathrm{m}^{3}\right)$ and lightweight concretes $\left(1000 \mathrm{~kg} / \mathrm{m}^{3}\right)$. We also presented the impact of the construction material used and its thickness on thermal comfort factors such as Predicted Mean Vote (PMV) and the number of hours with exceeded comfort temperature. Study provides guidelines and knowledge on choice between proper lightweight concrete type (lightweight aggregate concrete or foam concrete) depending on the climate zone. Through comprehensive research plan a valuable data for researchers and engineers is given to develop building envelopes with the most optimized thermal performances.

\section{Materials and methods}

\subsection{LWAC and FC properties}

Two types of concretes, with three density classes, were prepared to perform an evaluation of energy efficiency. Lightweight aggregate concrete (LWAC), with theoretical densities of 500, 750 and 1000 $\mathrm{kg} / \mathrm{m}^{3}$, as well as foamed concrete with theoretical densities of 500,750 , and $1000 \mathrm{~kg} / \mathrm{m}^{3}$, were developed and tested. The mixture design, production process and comprehensive evaluations of the concretes used in this study are available in our previous work [17]. For a better understanding of the differences between the pore structure of the used materials, micro-computed tomography (micro-CT) 3D images of the concretes were used, with the results presented in Figure 1. In the LWAC specimens, most of the porosity came directly from the lightweight aggregate used (grey color), while in the case of FC, the pores are in the matrix, since aggregates were not used. It can be seen that the number of pores in the specimen increased significantly with decreasing concrete density. 


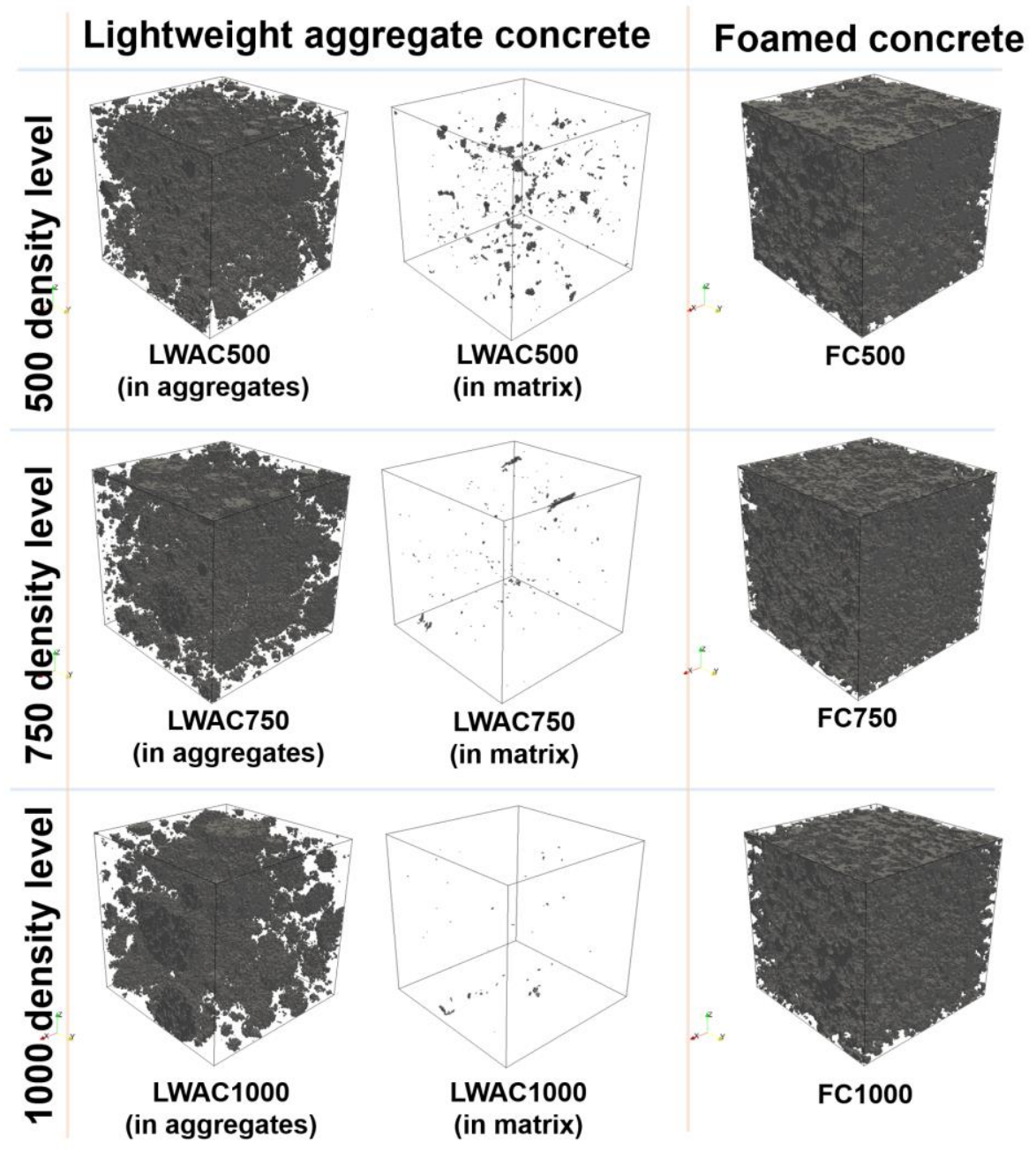

Figure 1. Pore structures of the LWAC (left and middle column) and FC specimens (right column), at different densities (Note: in each specimen, the left column show the inside the lightweight aggregates (grey), while the middle and right column show the pores within the matrix (grey).

The measured dry densities and basic thermal properties of all the variants tested, are presented in Table 1. The thermal characteristics of the LWCs were determined using the Hot Disk transient plane source method, according to ISO 22007-2 [18]. Prior to testing, cubic specimens with an edge length of 100 $\mathrm{mm}$ were oven-dried and cooled to room temperature at zero humidity conditions. Five measurements in each case were performed to increase accuracy, with the mean values taken as representative. 
Table 1. The dry densities and thermal properties of the concretes tested [17].

\begin{tabular}{cccccc}
\hline Material & $\begin{array}{c}\text { Dry } \\
\text { density } \\
\mathrm{kg} / \mathrm{m}^{3}\end{array}$ & $\begin{array}{c}\text { Thermal } \\
\text { conductivity } \\
\text { W/mK }\end{array}$ & $\begin{array}{c}\text { Volume } \\
\text { specific heat } \\
10^{6} \mathrm{~J} / \mathrm{m}^{3} \mathrm{~K}\end{array}$ & $\begin{array}{c}\text { Specific heat } \\
\mathrm{J} / \mathrm{kg} \mathrm{K}\end{array}$ & $\begin{array}{c}\text { Thermal } \\
\text { diffusivity } \\
10^{-6} \mathrm{~m}^{2} / \mathrm{s}\end{array}$ \\
\hline FC500 & 505 & 0.14 & 0.3386 & 670.50 & 0.413 \\
FC750 & 785 & 0.24 & 0.5626 & 716.69 & 0.427 \\
FC1000 & 930 & 0.31 & 0.9140 & 982.80 & 0.339 \\
LWAC500 & 500 & 0.14 & 0.4531 & 906.20 & 0.309 \\
LWAC750 & 695 & 0.22 & 0.7300 & 1050.36 & 0.301 \\
LWAC1000 & 940 & 0.33 & 1.1400 & 1212.77 & 0.289 \\
\hline
\end{tabular}

\subsection{Methods}

The energy performance calculations were made based on a typical, five-story multi-family building model. The external walls were assumed to be two-layer walls, consisting of an essential layer made from the lightweight concretes produced and a $10 \mathrm{~cm}$, foamed polystyrene insulating layer; one of the most commonly used insulating materials in Europe [19]. Both surfaces of the external wall were finished with conventional cement-based plaster rendering. The building analyzed is presented in Figure 1 (a). Due to a large number of envisaged variants, the repeatable parts of the building (without the ground floor or the last floor) were used for the calculations, thus making it possible to omit the impact of heat transfer to the ground and through the roof. This allowed an emphasis on differences between variants related to heat transfer through the external walls (Figure 2(b)) and to focus solely on the materials used in this study.

(a)

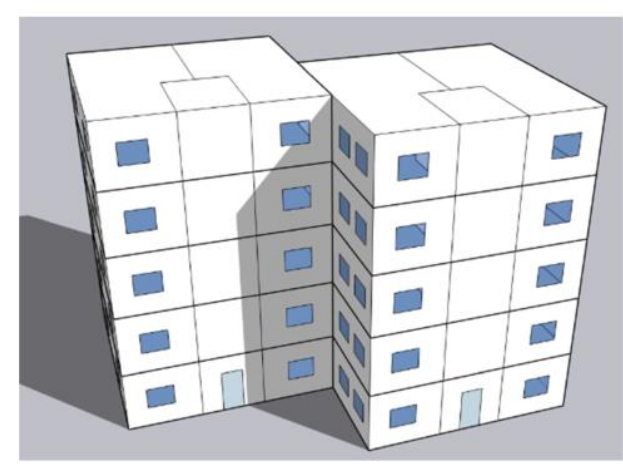

(b)

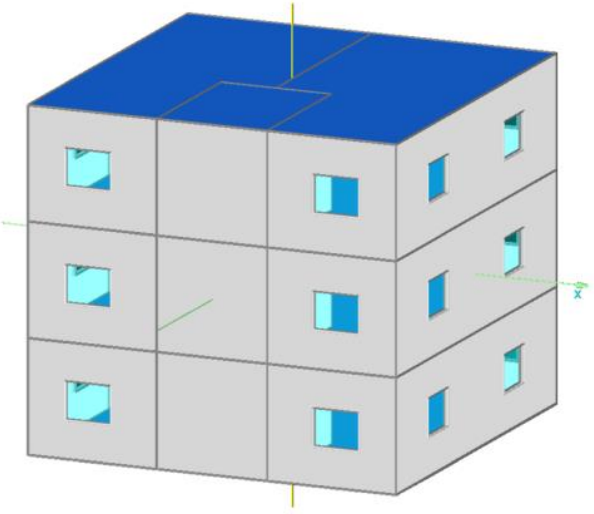

Figure 2. The multi-family building analyzed (a) and the model adopted for simulation (b). 
For all variants, the simulations were done on external walls of the same thermal transmittance, $U$, equal to $0.20 \mathrm{~W} /\left(\mathrm{m}^{2} \mathrm{~K}\right)$; which is the standard in Poland and in many other countries in Europe [20]. The parameters of the outer wall are presented in Table 2.

Table 2. Outer wall layer parameters.

\begin{tabular}{ccccc}
\hline No & Layer & $\begin{array}{c}\text { Layer } \\
\text { thickness } \\
\mathrm{m}\end{array}$ & $\begin{array}{c}\text { Thermal } \\
\text { conductivity } \\
\mathrm{W} / \mathrm{mK}\end{array}$ & $\begin{array}{c}\text { Thermal } \\
\text { resistance } \\
\left(\mathrm{m}^{2} \mathrm{~K}\right) / \mathrm{W}\end{array}$ \\
\hline- & Internal air & - & - & 0.130 \\
1 & Internal plaster & 0.005 & 0.800 & 0.006 \\
2 & Tested lightweight concretes & & Table 3 \\
3 & Foamed polystyrene & 0.100 & 0.033 & 3.030 \\
4 & External plaster & 0.004 & 1.200 & 0.003 \\
- & External air & - & - & 0.040 \\
\hline
\end{tabular}

To ensure that all the variants tested had the same $U$ values, the thicknesses of the support layers were adjusted accordingly, in such a way that in each variant the loadbearing layer had the same value of the thermal resistance, thus ensuring the same thermal transmittance value for the entire wall. The necessary thicknesses of the concrete layers are shown in Table 3, with the influence of a given material and its thickness on the thermal performance of the whole building, determined according to the data obtained. The theoretical thicknesses were calculated on the basis of the thermal conductivity of individual materials and the necessary thermal resistance, which enables to obtain thermal transmittance at the level of $0.2 \mathrm{~W} /\left(\mathrm{m}^{2} \mathrm{~K}\right)$ of the entire wall. It can be clearly seen that a significant reduction in wall thickness could be achieved by decreasing concrete density.

Table 3. The required thickness and thermal resistance of the external wall layer.

\begin{tabular}{cccc}
\hline Material & $\begin{array}{c}\text { Theoretically } \\
\text { required } \\
\text { thickness } \\
\mathrm{m}\end{array}$ & $\begin{array}{c}\text { Design } \\
\text { thermal } \\
\text { resistance } \\
\left(\mathrm{m}^{2} \mathrm{~K}\right) / \mathrm{W}\end{array}$ & $\begin{array}{c}\text { Thermal } \\
\text { transmittance } \\
\mathrm{W} /\left(\mathrm{m}^{2} \mathrm{~K}\right)\end{array}$ \\
\hline FC500 & 0.251 & & \\
FC750 & 0.430 & & \\
FC1000 & 0.555 & 1.790 & 0.20 \\
LWAC500 & 0.251 & & \\
LWAC750 & 0.394 & & \\
LWAC1000 & 0.591 & & \\
\hline
\end{tabular}


The calculations were undertaken at four different locations. This allowed the determination of the impact of each variant used, in different climatic conditions. For a hot climate, the data for Cairo (Egypt, $T_{\text {average }}=21.7^{\circ} \mathrm{C}, T_{\max }=43.0^{\circ} \mathrm{C}$ and $T_{\min }=7.0^{\circ} \mathrm{C}$ ) was used. A moderate, warm climate was represented by Vienna (Austria, $T_{\text {average }}=10.4^{\circ} \mathrm{C}, T_{\max }=32.4^{\circ} \mathrm{C}$ and $T_{\min }=-10.9^{\circ} \mathrm{C}$ ), a moderate cold climate by Kołobrzeg (Poland, $T_{\text {average }}=8.6^{\circ} \mathrm{C}, T_{\max }=29.7^{\circ} \mathrm{C}$ and $T_{\min }=-9.8^{\circ} \mathrm{C}$ ) and a cold climate by Tromsoe (Norway, $T_{\text {average }}=2.1^{\circ} \mathrm{C}, T_{\max }=22.0^{\circ} \mathrm{C}$ and $T_{\min }=-14.2^{\circ} \mathrm{C}$ ). The average external air temperatures in the test locations are presented in Figure 3.

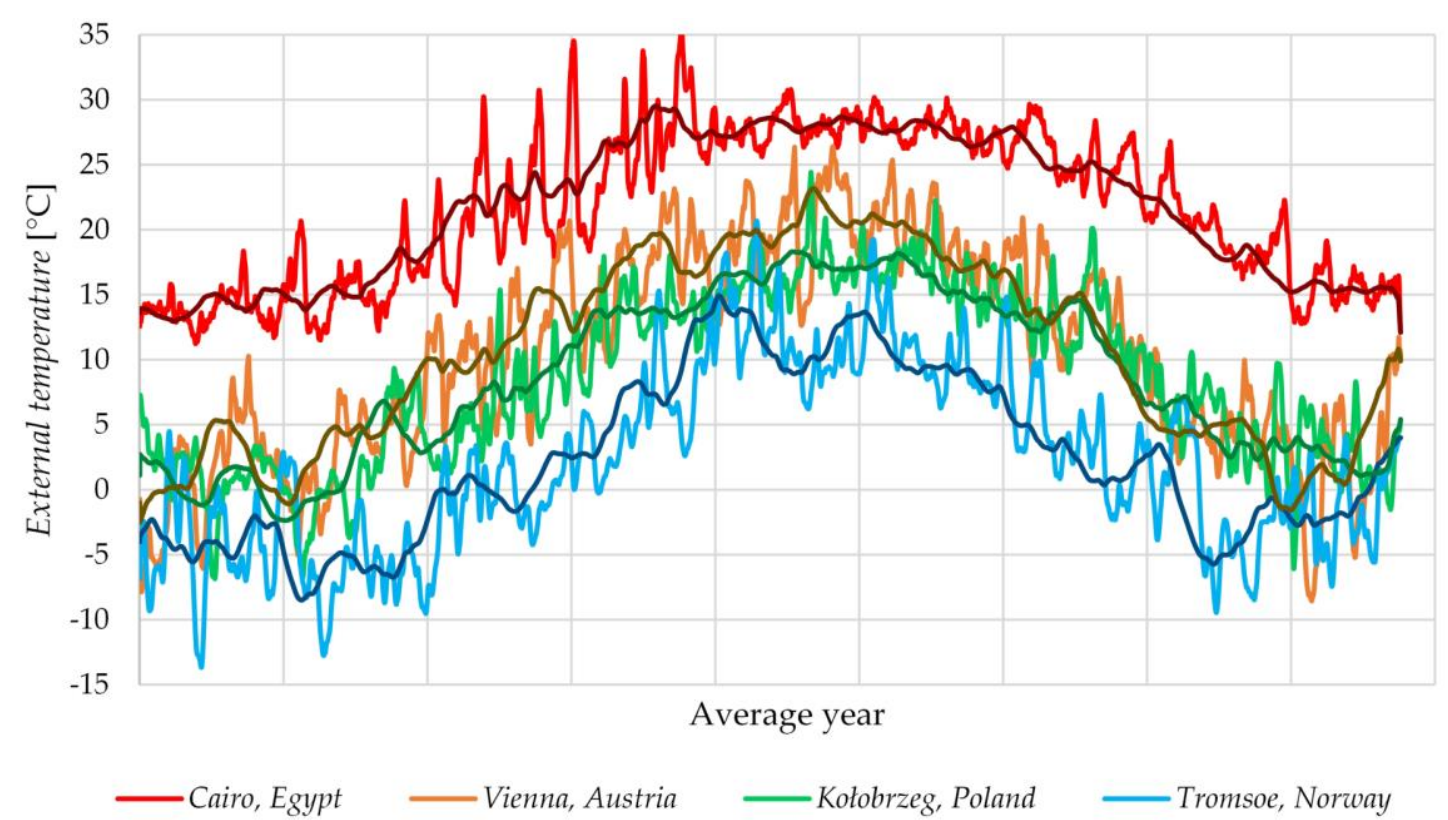

Figure 3. The average external temperatures in the test locations.

The building thermal performance analysis was done using WUFI Plus software, which makes it possible to analyze a whole building as a model that connects energetic building simulation and hygrothermal component calculation. Transient heat and moisture transports were calculated simultaneously at arbitrary time steps, during an arbitrary simulation period. The calculation was performed using the finite volumes method. Validation studies of this software have been presented, among others, in [21], [22].

The parts of the building analyzed were the three middle floors, each with an internal useable area of $100 \mathrm{~m}^{2}$. The simulation was performed for the full calendar year. The internal walls and floors above and below the analyzed part of the building were assumed to be adiabatic boundaries, due to the 
proximity of a story with a similar internal temperature. All the inner walls were assumed to be $24 \mathrm{~cm}$ thick with a cement-lime plaster finish.

The windows in the model, with a total area 1/8 of the total internal useable area, were modeled as triple glazed windows with a thermal transmittance $U=0.90 \mathrm{~W} /\left(\mathrm{m}^{2} \mathrm{~K}\right)$. The model did not take into account any sunshade or solar control systems. $40 \%$ of the window surface area was located on the southern building face, while on other faces the window area was $20 \%$ each. The ceilings were taken to be monolithic reinforced concrete with a layer of sound insulation made of foamed polystyrene.

The simulations were performed in two variants: with a cooling system and without it. The assumed minimum internal temperature was equal to $20^{\circ} \mathrm{C}$ and the maximum temperature, in the variant with cooling, was $24^{\circ} \mathrm{C}$. The analysis included mechanical ventilation, providing air exchange at three different rates: $0.5,1.0$ and $1.5 \mathrm{1} / \mathrm{h}$. Additional infiltration through leaks in the building envelope was set to a constant, equal to $0.1 \mathrm{1} / \mathrm{h}$ for all variants. Internal heat gains were constant and the same in all variants and locations. No ventilation heat recovery was taken into account. Overall, 144 variants were simulated: 6 external wall types, 4 locations, 3 ventilation rates and two cooling system variants.

\section{Results}

\subsection{Dynamic thermal characteristics}

Before performing the main thermal performance simulations, the dynamic thermal characteristics of the variants of the external wall were calculated, according to the EN ISO 13786 [23] standard. The calculations were done for a 24-hour fluctuating temperature period. The heat transfer matrix for the six tested wall variants was calculated according to the following equation (Eq.1):

$$
\left[\begin{array}{l}
\widehat{\Theta}_{e} \\
\widehat{\mathrm{q}}_{e}
\end{array}\right]=\left[\begin{array}{ll}
Z_{11} & Z_{12} \\
Z_{21} & Z_{22}
\end{array}\right] \cdot\left[\begin{array}{l}
\widehat{\Theta}_{i} \\
\widehat{\mathrm{q}}_{i}
\end{array}\right]
$$

where:

$Z_{m n}-$ calculated matrix elements based on periodic heat penetration depth,

$\hat{\Theta}_{n}$ and $\hat{q}_{n}-$ average values of temperature and heat flow. 
The dynamic thermal characteristics were calculated on the basis of the transfer matrix. Figure 4 presents the internal thermal admittances, $Y_{l l}$, and the internal areal heat capacities, $K_{l}$, of each variant. The admittance and heat capacity values increased with increases in the wall layer thickness. Despite comparable thermal conductivity values for FC and LWAC in the corresponding density groups, noticeable differences in the specific heat and thermal diffusivity values were observed. This is attributable to the mixture composition and thermal characteristics of their constituents (aggregate particles in the case of LWAC) as well as pore structure and dry density. Variants FC1000 and LWAC1000 were characterized by significantly higher thermal conductivity values. Consequently, solutions based on these materials should allow better use of thermal energy accumulated in the building wall components. Due to higher LWAC volume-specific heat values, slightly higher values for both thermal admittance and heat capacity were achieved in the case of LWAC.

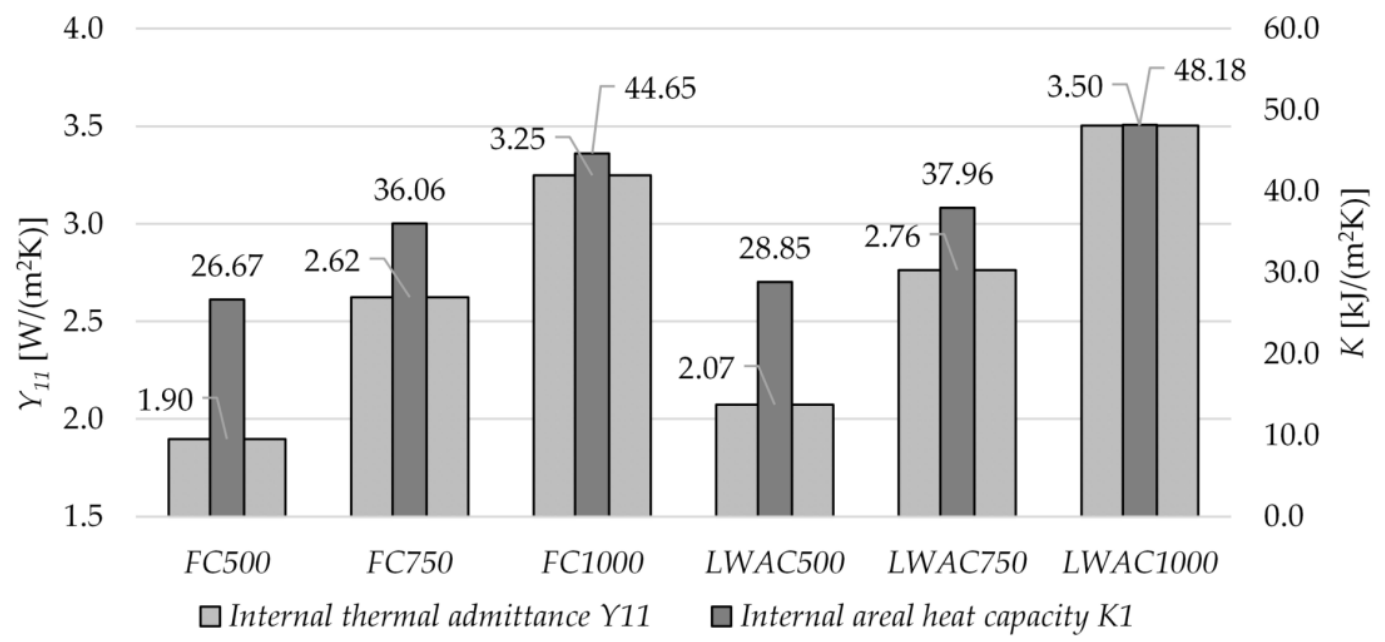

Figure 4. The internal thermal admittance, $Y_{l l}$, and internal areal heat capacity, $K_{l}$, values of the external wall variants tested.

Figure 5 presents the periodic thermal transmittances, $Y_{l l}$, of each variant, calculated for 24-hour temperature fluctuations. Variants based on less dense wall materials were characterized by higher, more unfavorable thermal transmittance values. However, it should be noted that very low values were obtained for all the variants. The higher LWAC volume heat capacity values caused a significant reduction in periodic thermal transmittance, compared to FC with the same density. 


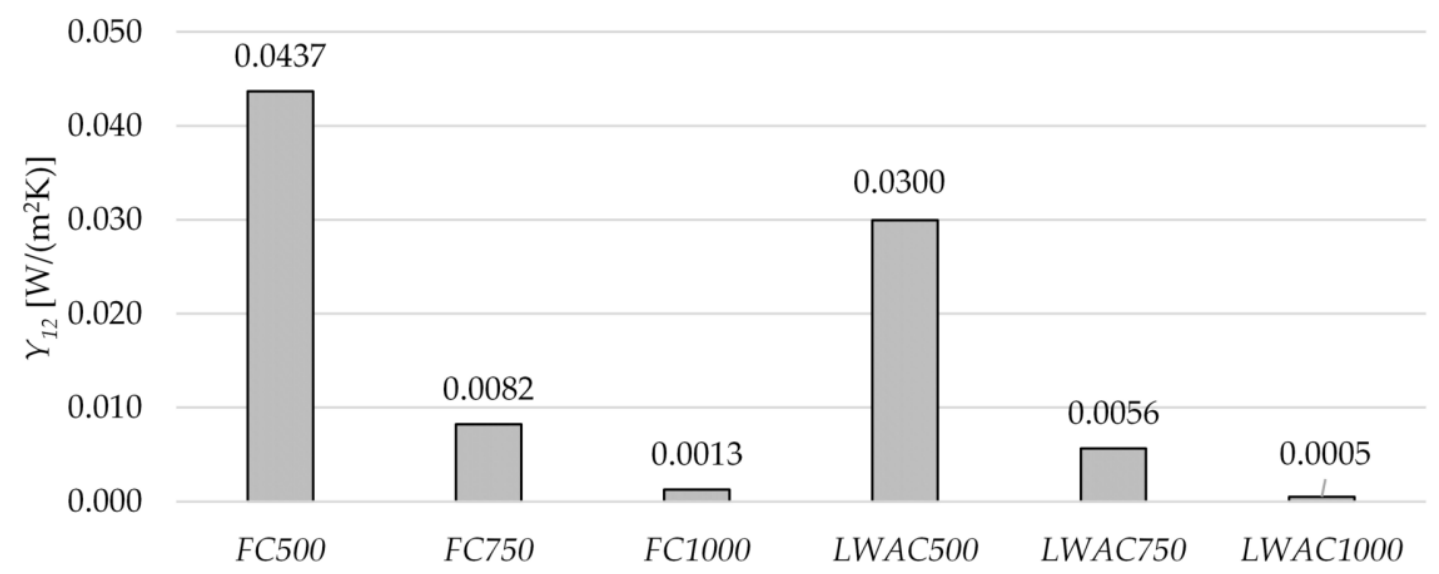

Figure 5. The periodic thermal transmittance values, $Y_{11}$, of the external wall variants tested.

The thermal transmittance values, which affected the decrement factors obtained, are shown in Figure 6 , where it can be clearly seen that the lowest values were achieved for variants with the thickest wall layers; FC1000 and LWAC1000. It should be noted that higher time shifts were obtained for the lightest wall variants based on materials with the lowest thermal conductivity (FC500 and LWAC500).

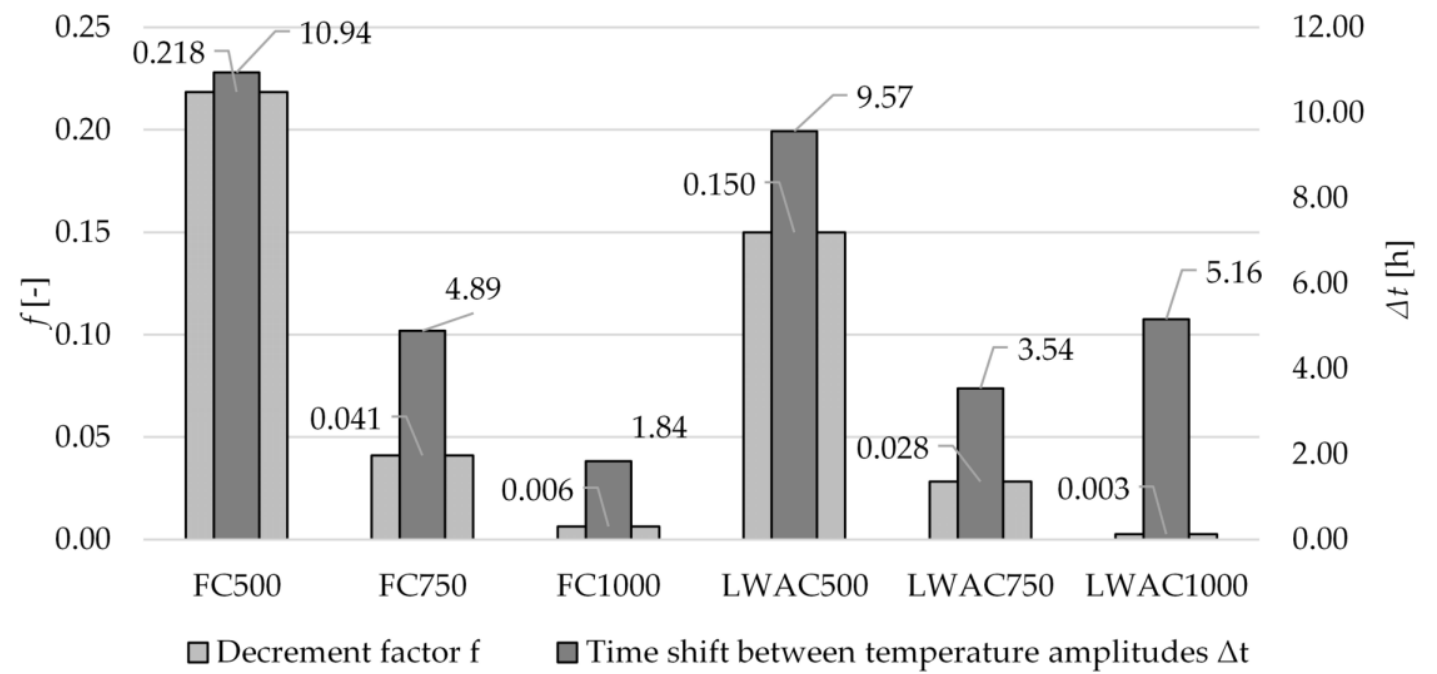

Figure 6. The decrement factor $f$ and the time shift between temperature amplitudes values, $\Delta t$, of the external wall variants, tested.

In addition, a difference between FC and LWAC can also be distinguished: due to LWACs higher volume-specific heat values, of a reduction in the decrement factor values, in comparison to the corresponding FCs variants, can be seen. 


\subsection{Heating and cooling demand}

In Figure 7, exemplary heating demand graphs for the whole year are presented. To improve the readability of this manuscript, it was decided to show values for only one type of wall, i.e. based on LWAC500, with two ventilation level values of 0.5 and 1.5 changes per hour. There were visible differences in heating demand in each location, as well as an increase in heating demand with an increase in the air exchange rate.

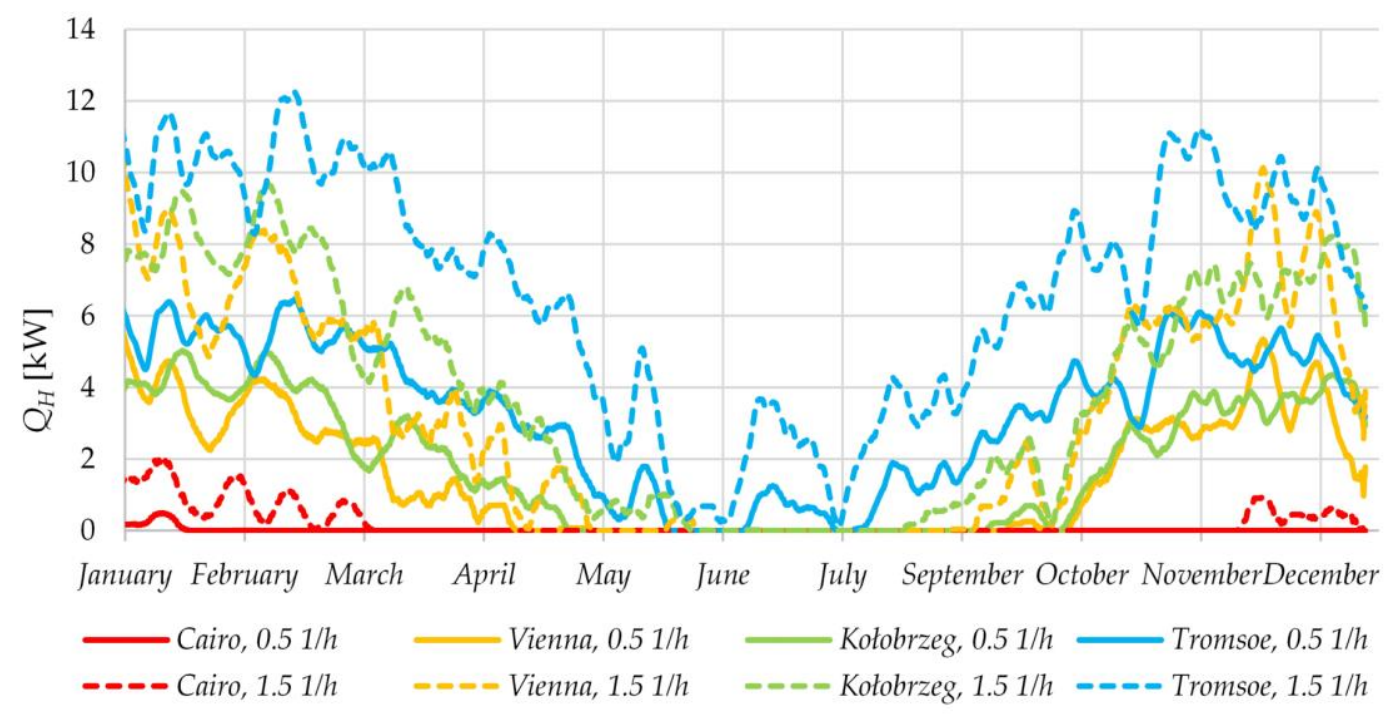

Figure 7. The exemplary heating demand diagram for variants based on LWAC500 in different locations and with different levels of ventilation.

The heating demand, $Q_{H, n d}$, for all the variants with a cooling system is shown in Figure 8 . The charts on the left show the absolute values for a full year of building use. The graphs on the right show the relative results, in relation to the six variants based on walls with a material density of $1000 \mathrm{~kg} / \mathrm{m}^{3}$ (LWAC1000 and FC1000). Efforts were made to keep the same scale on the vertical axis so that variants in different locations could be compared. All the other figures presented in this publication were prepared similarly.

The highest differences were observed in moderate climates (Kołobrzeg and Vienna). The differences in heating demand between the lightest and heaviest variants were between $12 \%$ and $14 \%$, respectively. These differences occurred at ventilation levels of 0.5 and $1.01 / \mathrm{h}$. With higher air exchange rates, the influence of accumulation and the thickness of the wall layer was lower $-1 \%$ and $3 \%$, respectively. The very high differences in the relative results for Cairo (Figure 8a) were a result of comparing very small 
heating demand values at this location. These differences are insignificant due to virtually no heating demand or only a very small one. In the case of the cold climate, the differences were also large, ranging from $10 \%$ to $12 \%$ according to the ventilation rate $(0.5$ and $1.01 / \mathrm{h})$. In all the locations, a slight advantage in the LWAC-based solutions was visible. In the LWAC walls, higher changes in the relative results of heating demand were observed, in comparison to the FC variants.

(a) Cairo, Egypt

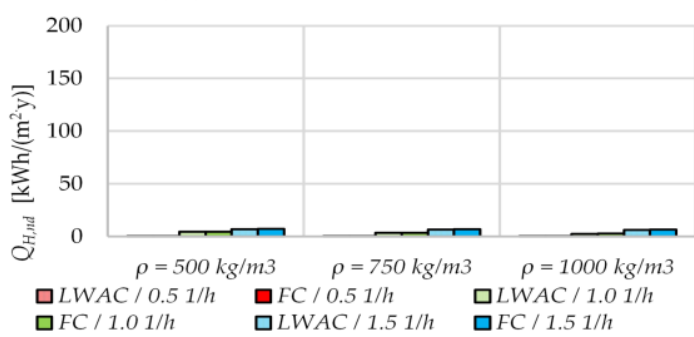

(b) Vienna, Austria

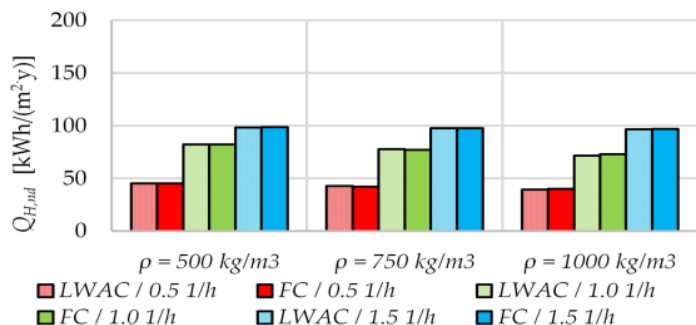

(c) Kołobrzeg, Poland

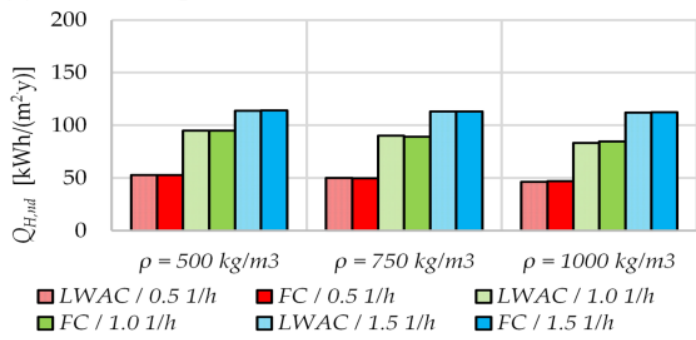

(d) Tromsoe, Norway

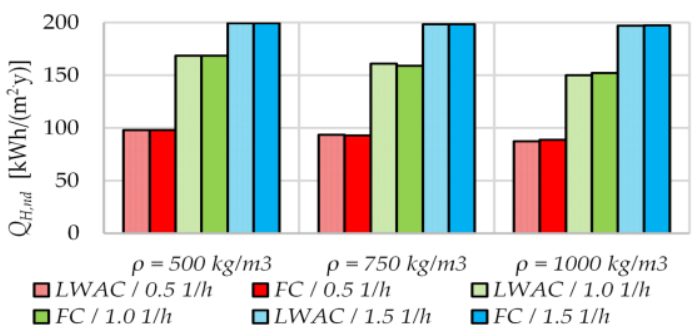

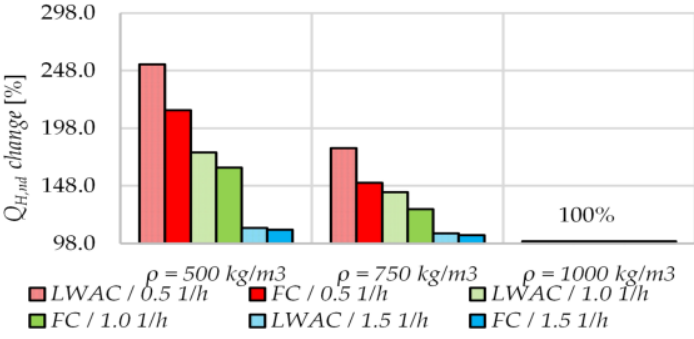
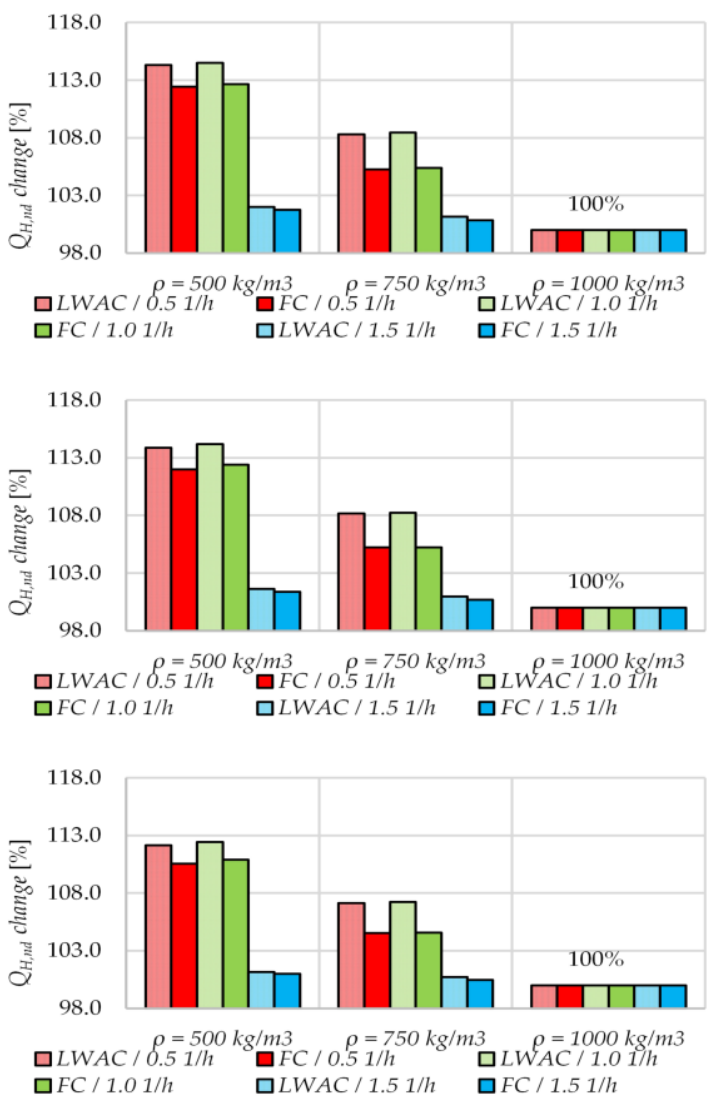

Figure 8. Heating demand, $Q_{H, n d}$, for building variants with a cooling system.

In Figure 9, the maximum hourly heating demand, $Q_{H, \max }$, for the variants with a cooling system is shown. The use of thick walls resulted in a reduction in the maximum instantaneous demand by 12-15 $\%$ in the case of Tromsoe, $12-13 \%$ in Kołobrzeg and 15-16 \% in Vienna. The greatest differences were 
observed in variants with the low ventilation level of $0.51 / \mathrm{h}$; with high air exchange, the differences were much smaller. The greatest changes in instantaneous heating demand were observed in Cairo. However, in these variants the absolute values were about three times smaller than in the other locations. In summary, the warmer the climate, the greater the differences in the instantaneous heating demand between the various wall thickness variants. Moreover, slightly lower changes were reported for FC in almost all cases and locations. The higher changes in the LWAC solutions were due to the higher volume specific heat of the LWAC, in comparison to the FC variants.

(a) Cairo, Egypt
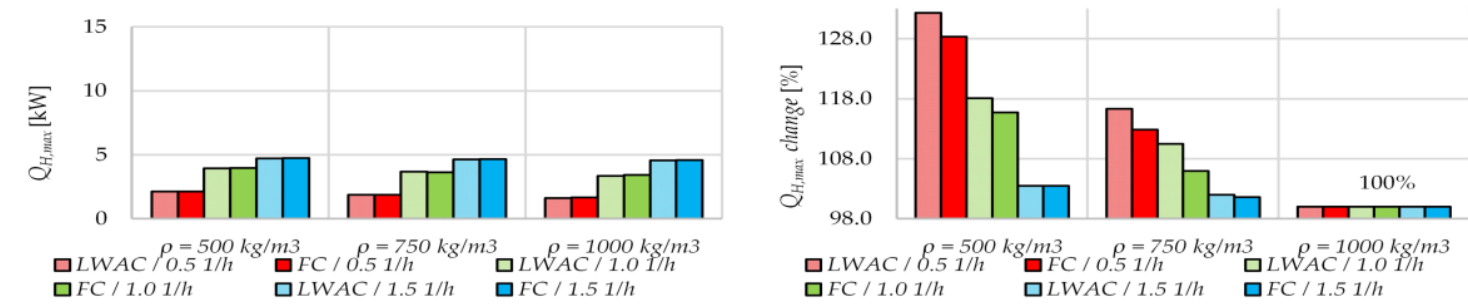

(b) Vienna, Austria
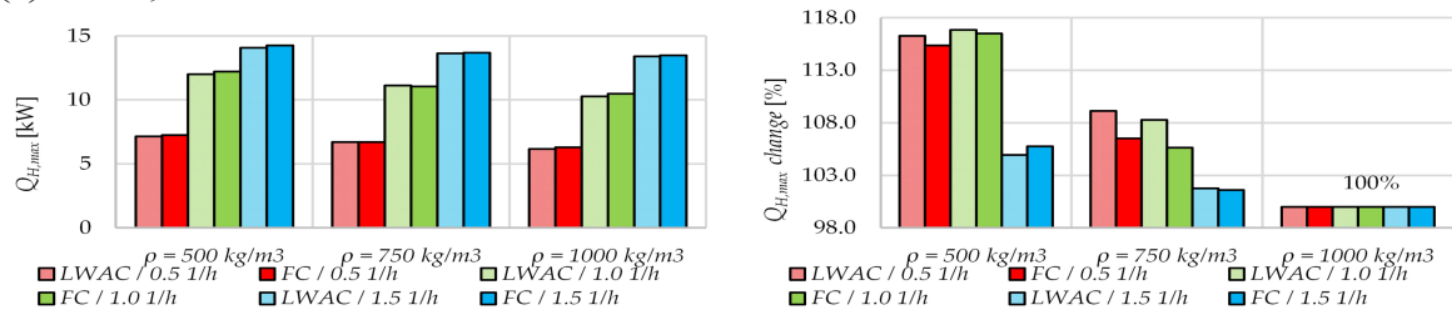

(c) Kołobrzeg, Poland
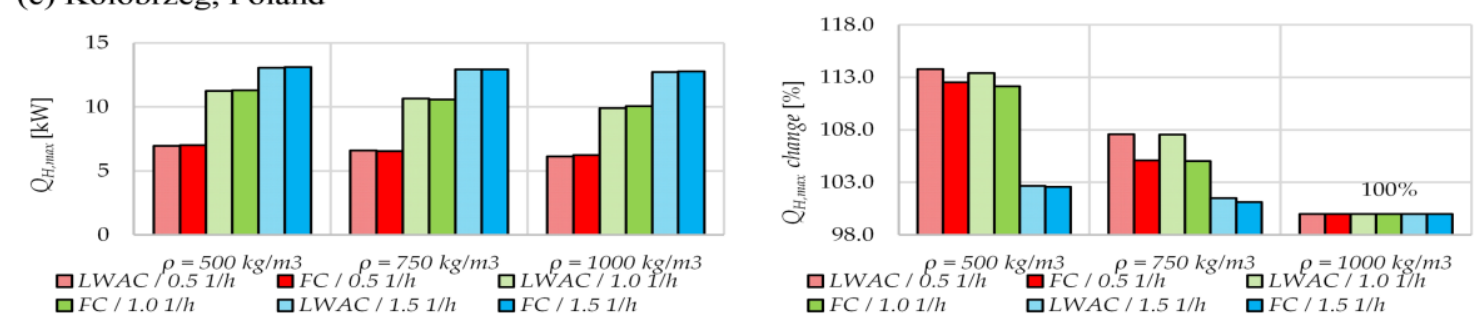

(d) Tromsoe, Norway
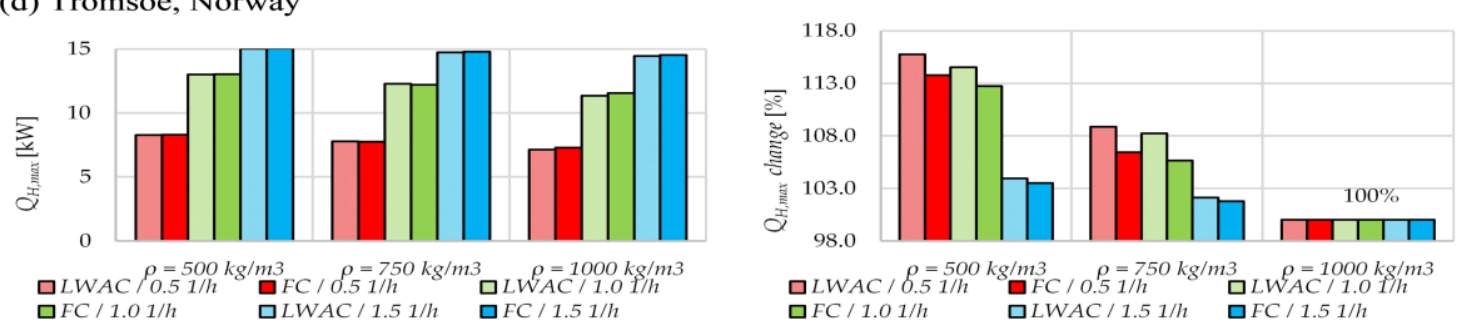

Figure 9. Maximum hourly heating demand, $Q_{H, \max }$, for building variants with a cooling system. 
The results of exemplary cooling demand for the variants based on LWAC500, are shown in Figure 10. In distinction to heating demand, the dominant demand was in Cairo, followed by Vienna. The minimum values were in Kołobrzeg and Tromsoe.

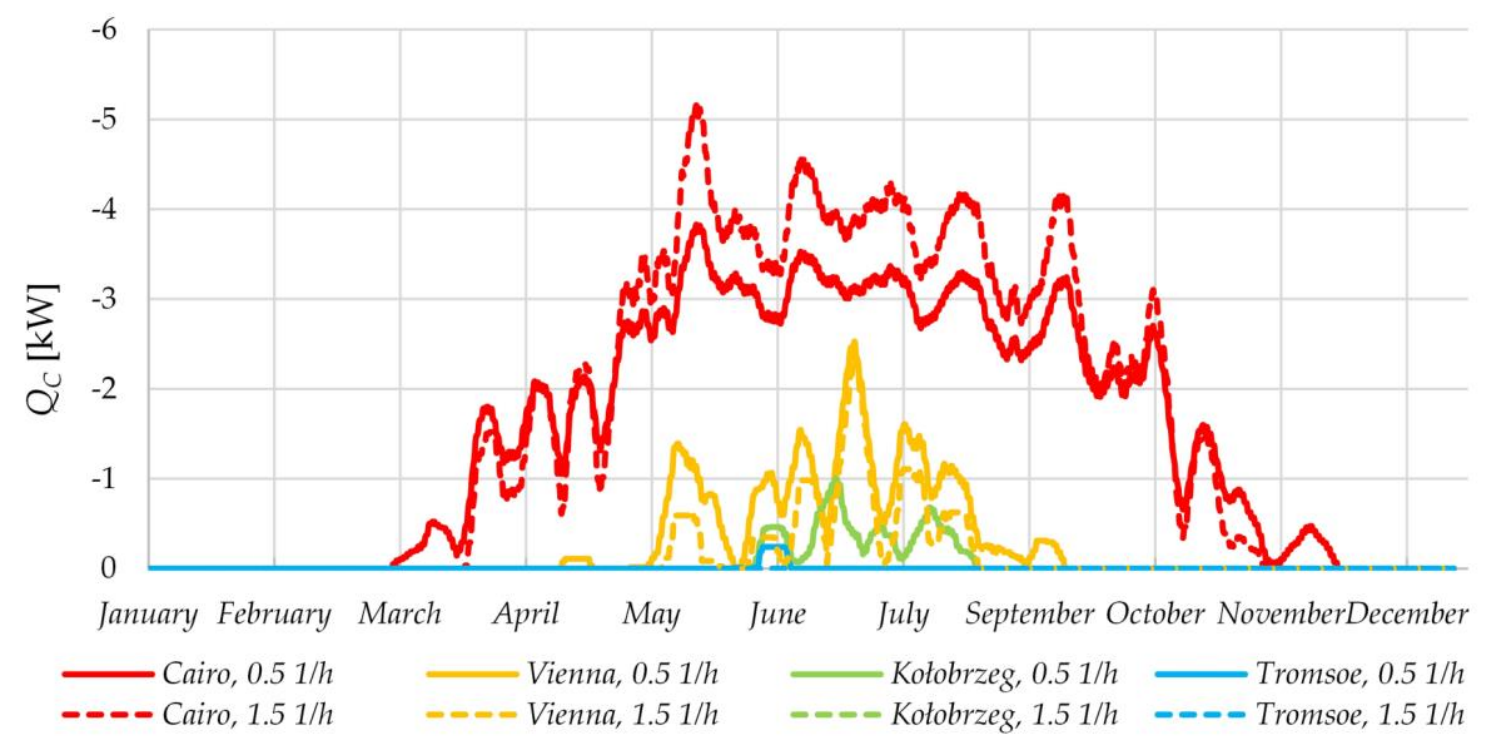

Figure 10. Exemplary cooling demand diagram for the variants based on LWAC500, in different locations and at different levels of ventilation.

The cooling demand for the variants with a cooling system is presented in Figure 11. In the variants located in Cairo, the greatest differences were observed with the ventilation set at $1.01 / \mathrm{h}$. In this case, the thickest wall variants had approximately $3 \%$ less cooling demand. Both higher and lower levels of ventilation resulted in significantly smaller differences in cooling demand, which oscillated around $1 \%$. Large relative differences of over $20 \%$ were noted in Vienna, where there was a strong ventilation rate of $1.5 \mathrm{l} / \mathrm{h}$, but the differences were small in the other cases. In the moderately cold (Kołobrzeg) and cold (Tromsoe) variants, the differences were insignificant due to the low cooling demand. 
(a) Cairo, Egypt
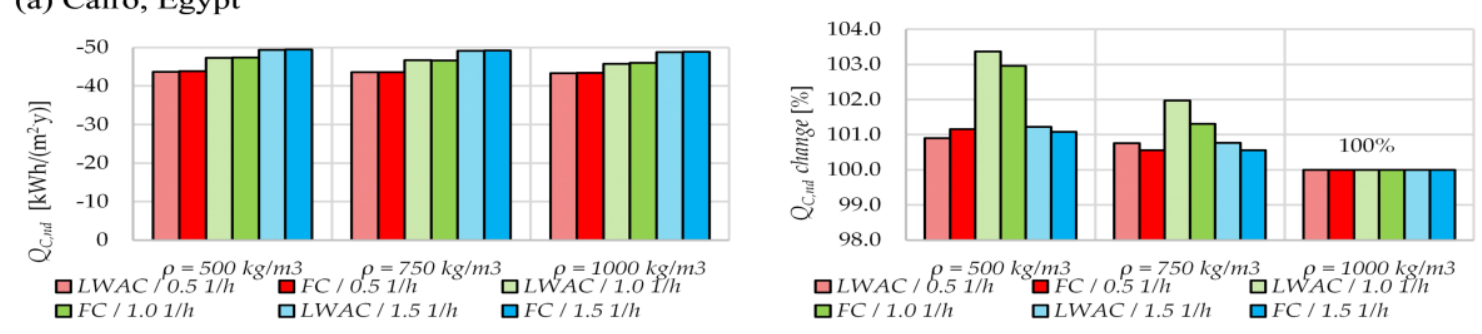

(b) Vienna, Austria
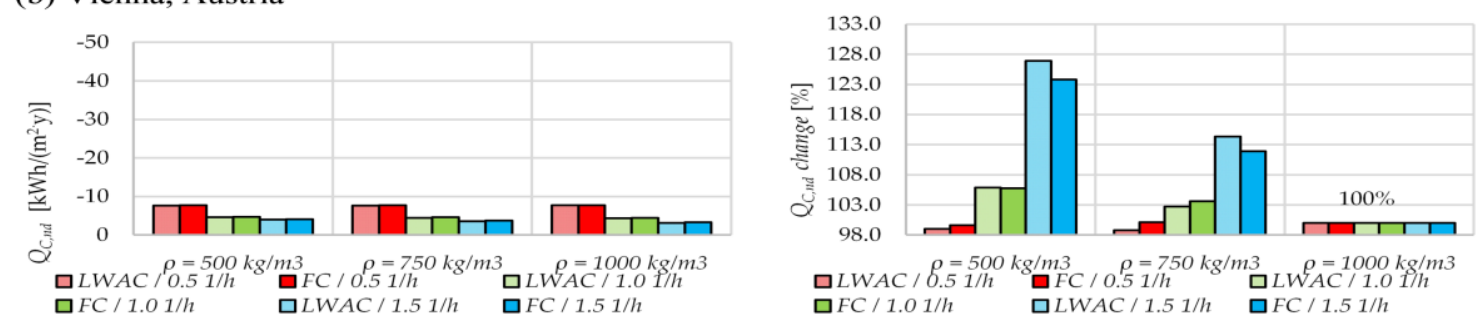

(c) Kołobrzeg, Poland
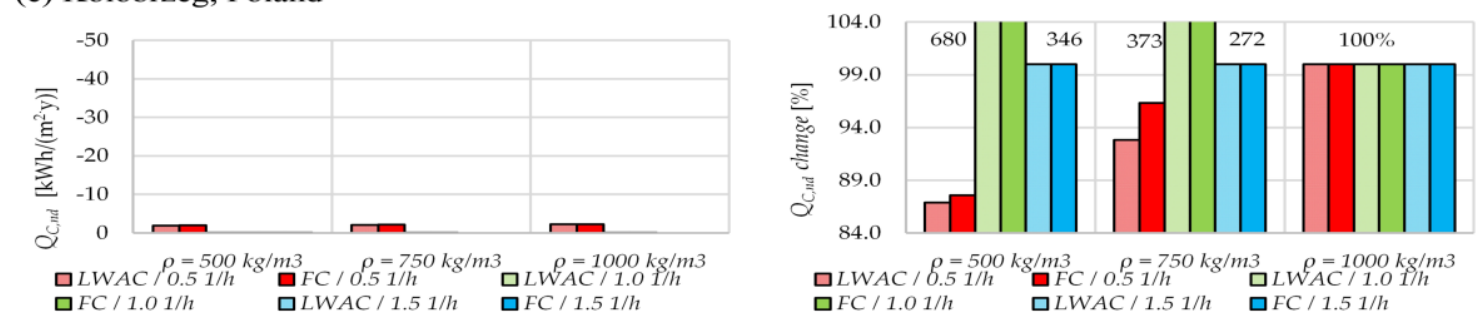

(d) Tromsoe, Norway
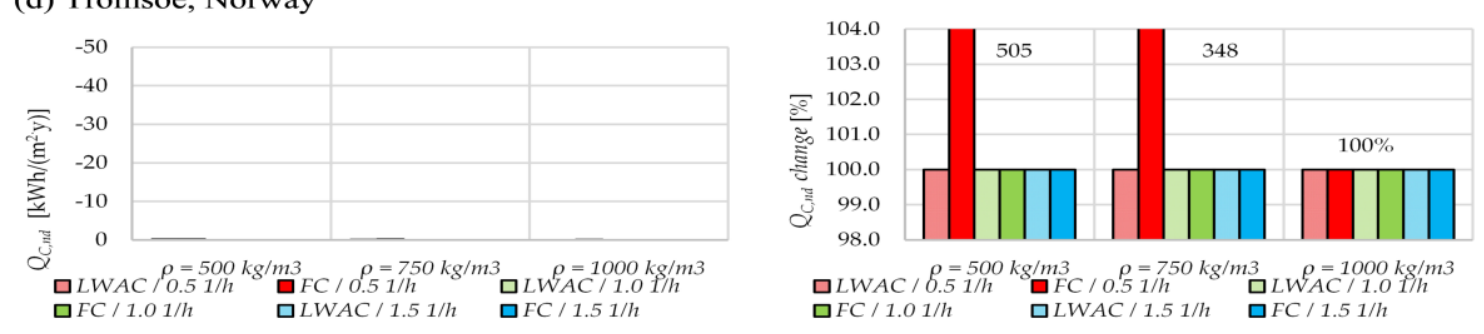

Figure 11. Cooling demand, $Q_{C, n d}$, for building variants with a cooling system.

Figure 12 shows the maximum hourly cooling demand. Large differences were observed in the case of locations requiring a cooling system (Cairo and Vienna). The greatest differences, between 10 and 13\%, were found at ventilation levels of 0.5 and $1.01 / \mathrm{h}$. The overly high ventilation level of $1.51 / \mathrm{h}$ reduced the influence of the thickness and heat accumulation of the wall layer, on the temporary cooling demand. Again, in the case of variants with cold climates, the influence of the base layer was limited. 
(a) Cairo, Egypt
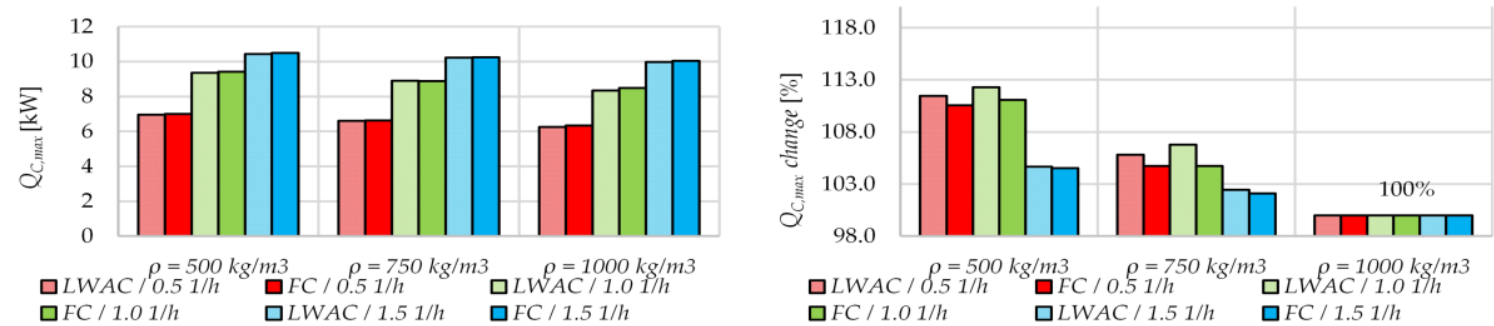

(b) Vienna, Austria
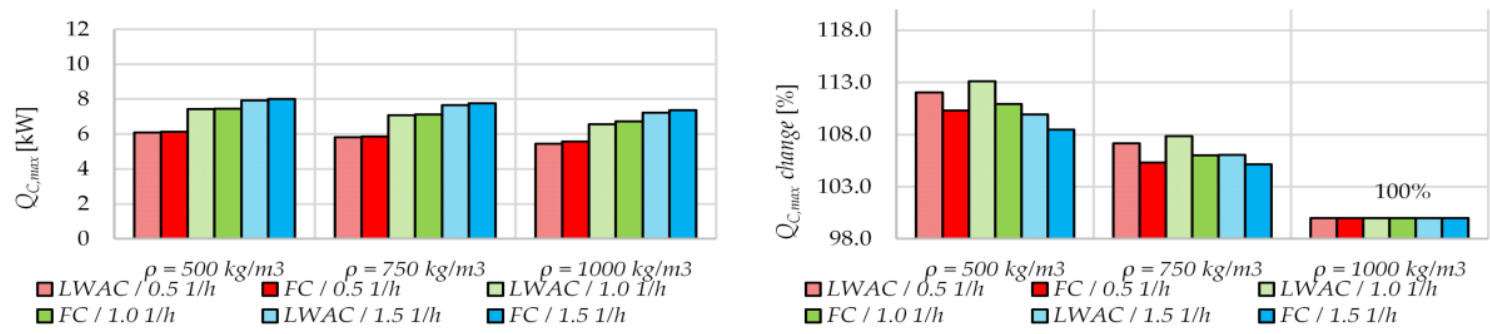

(c) Kołobrzeg, Poland
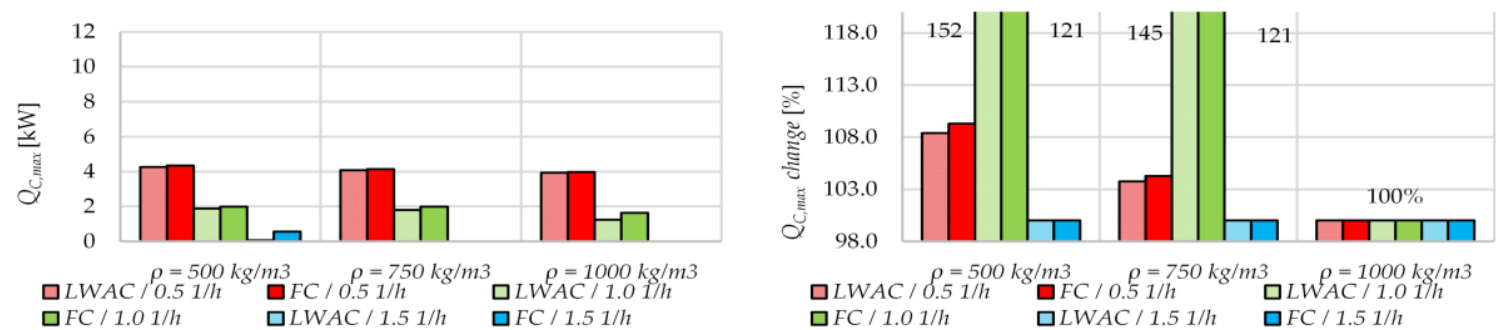

(d) Tromsoe, Norway
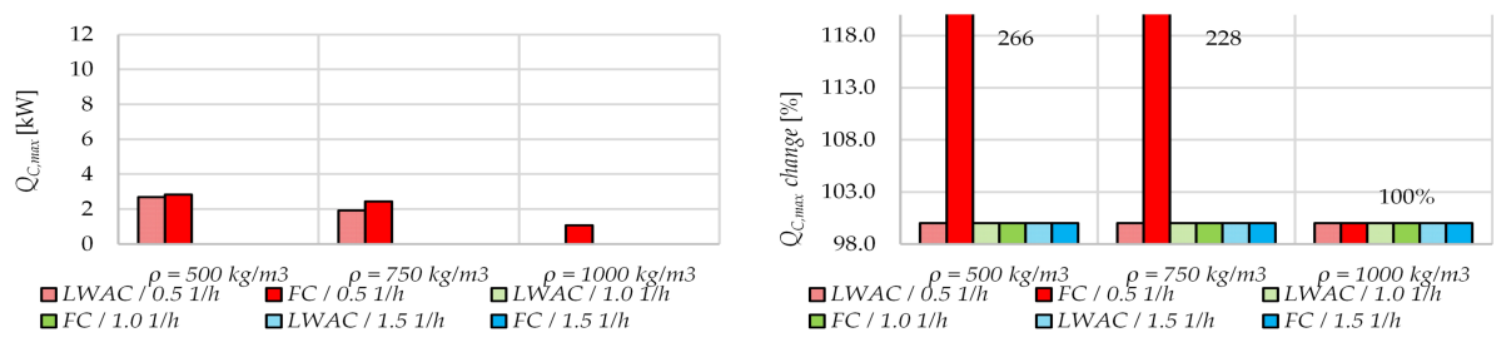

Figure 12. Maximum hourly cooling demand, $Q_{H, m a c}$, for building variants with a cooling system.

\subsection{Predicted mean vote $(\mathrm{PMV})$}

The predicted mean vote index (PMV) values for the exemplary variants, based on LWAC500, are presented In Figure 13, All the variants had approximate values between -1 (slightly cool) to +1 (slightly warm) for the whole year, which means that thermal comfort was maintained for all of them throughout the entire calendar year. The sum of the absolute PMV values for the whole year was determined on the basis of the measurements for each variant. The lower the $\sum|\mathrm{PMV}|$ value obtained, the better the thermal comfort of a given variant. 


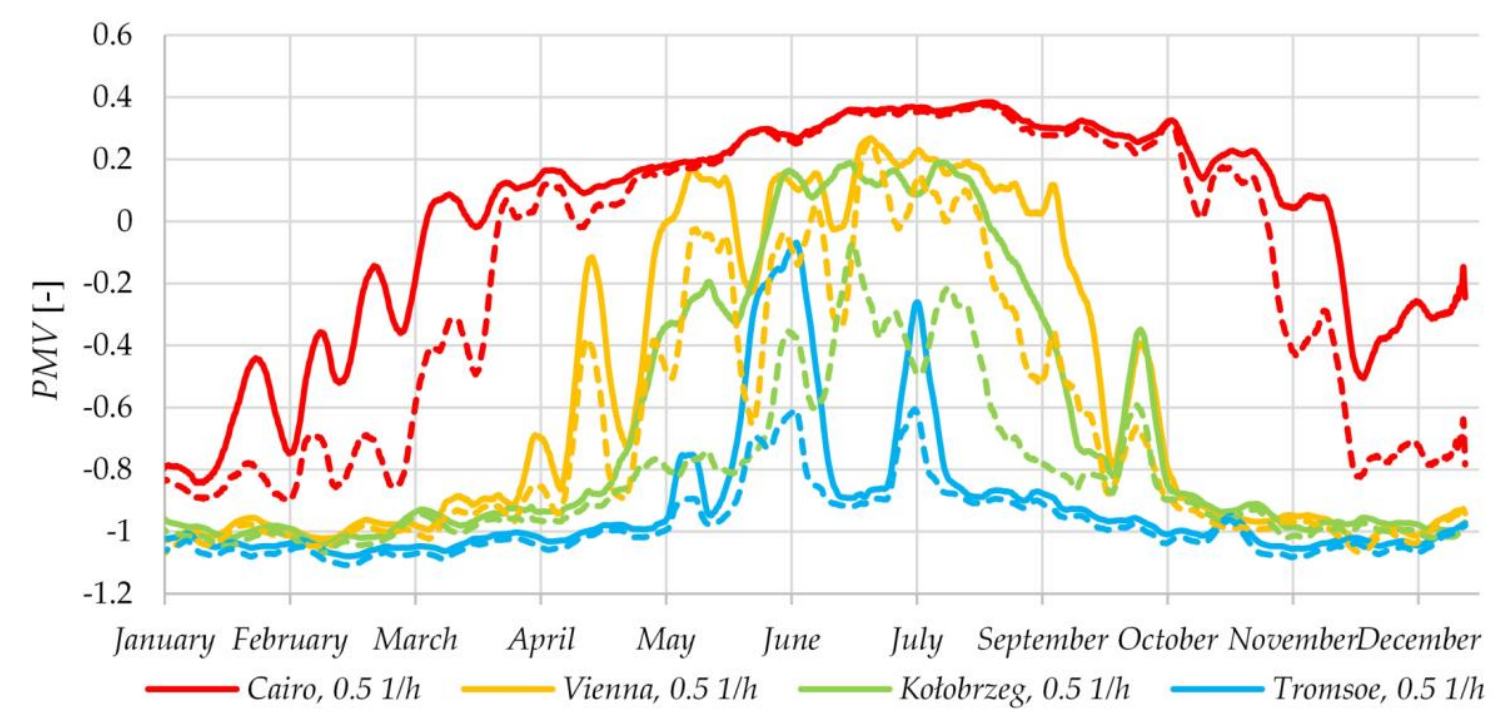

Figure 13. Exemplary PMV diagram for variants based on LWAC500, in different locations and at different levels of ventilation, with a cooling system.

Figure 14 shows the values of the annual $\sum|\mathrm{PMV}|$ for the variants with a cooling system. The warmer the climate at a given location, the greater the differences between the variants. Particularly large differences occurred in variants with a ventilation level of $0.5 \mathrm{1} / \mathrm{h}$. In Cairo, the differences between the thinnest and lightest walls were 5-6\%. In Vienna and Kołobrzeg, the differences at this level of ventilation amounted to about $2 \%$ in favor of the thickest variant. The differences in Tromsoe were negligible. The results were opposite in highly ventilated variants $(1.51 / \mathrm{h})$. Better results were obtained for thinner walls with a lower thermal conductivity coefficient (LWAC500 and FC500). In general, in almost all the variants, differences between LWAC and FC variants were observed. Due to the higher specific heat of the LWAC variants, the PMV change values between different wall layer densities were higher in the LWAC variants. 
(a) Cairo, Egypt
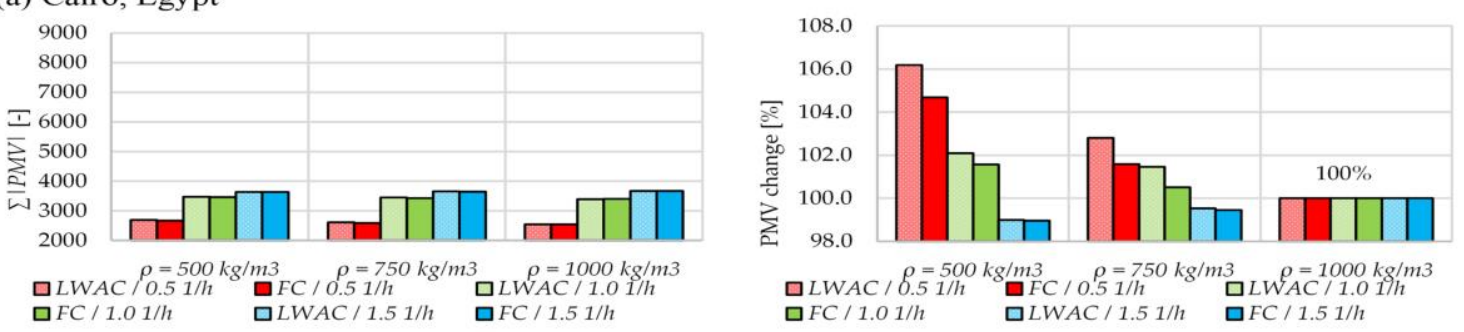

(b) Vienna, Austria
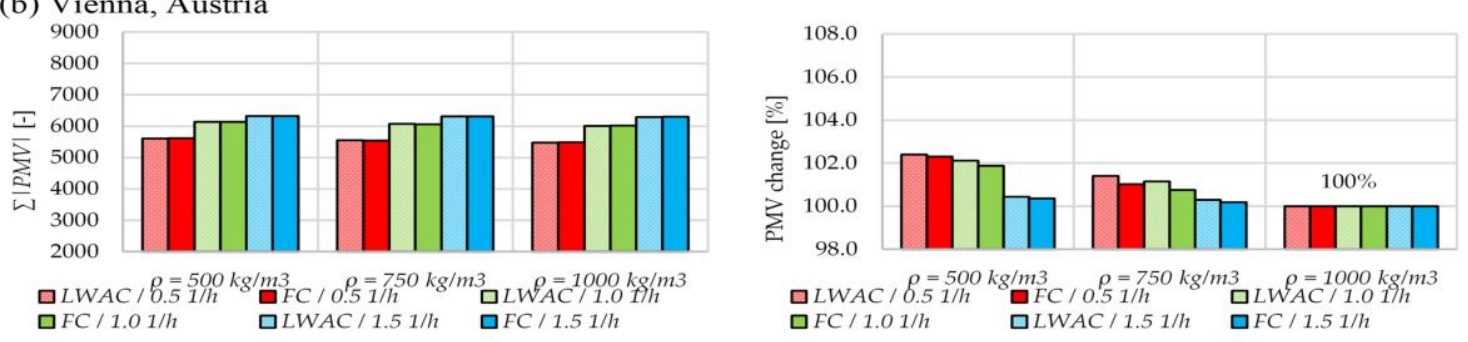

(c) Kołobrzeg, Poland
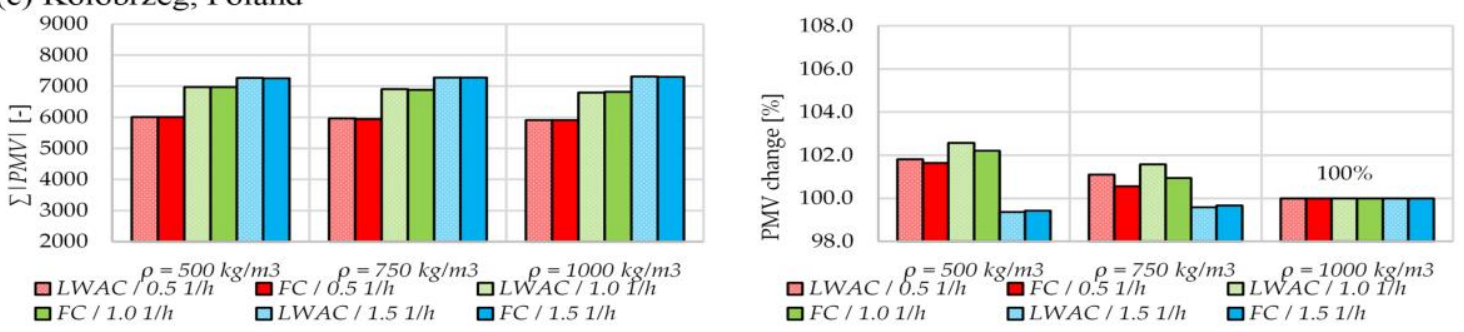

(d) Tromsoe, Norway
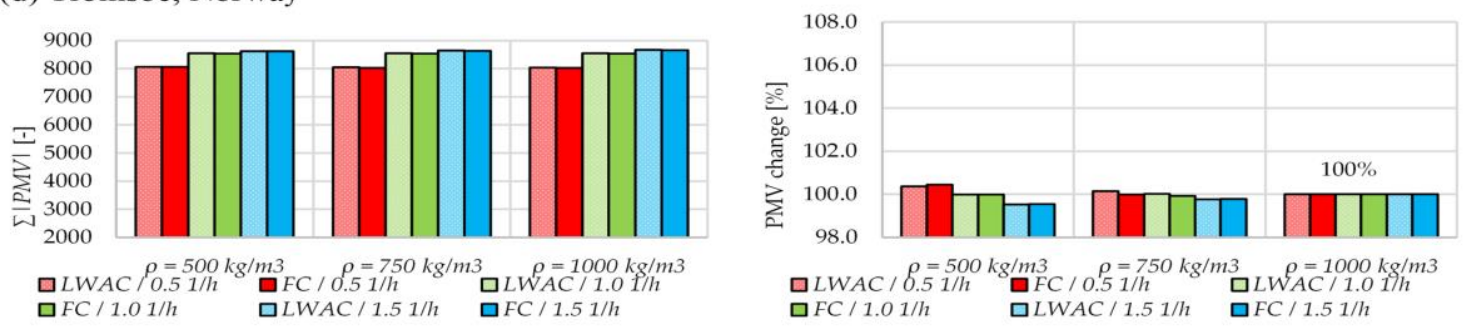

Figure 14. Annual, total $|\mathrm{PVM}|$ for building variants with a cooling system.

In Figure 15, the values of the predicted mean vote index (PMV) are presented for exemplary variants based on LWAC500, but without a cooling system. This caused an significant increase in PMV values. In the case of Cairo, at a ventilation level of $0.51 / \mathrm{h}$, thermal comfort was exceeded beyond the upper PMV scale (PMV> 3). An increase in PMV was also observed at other locations, but it was not as significant as in the case of the hot climate. 


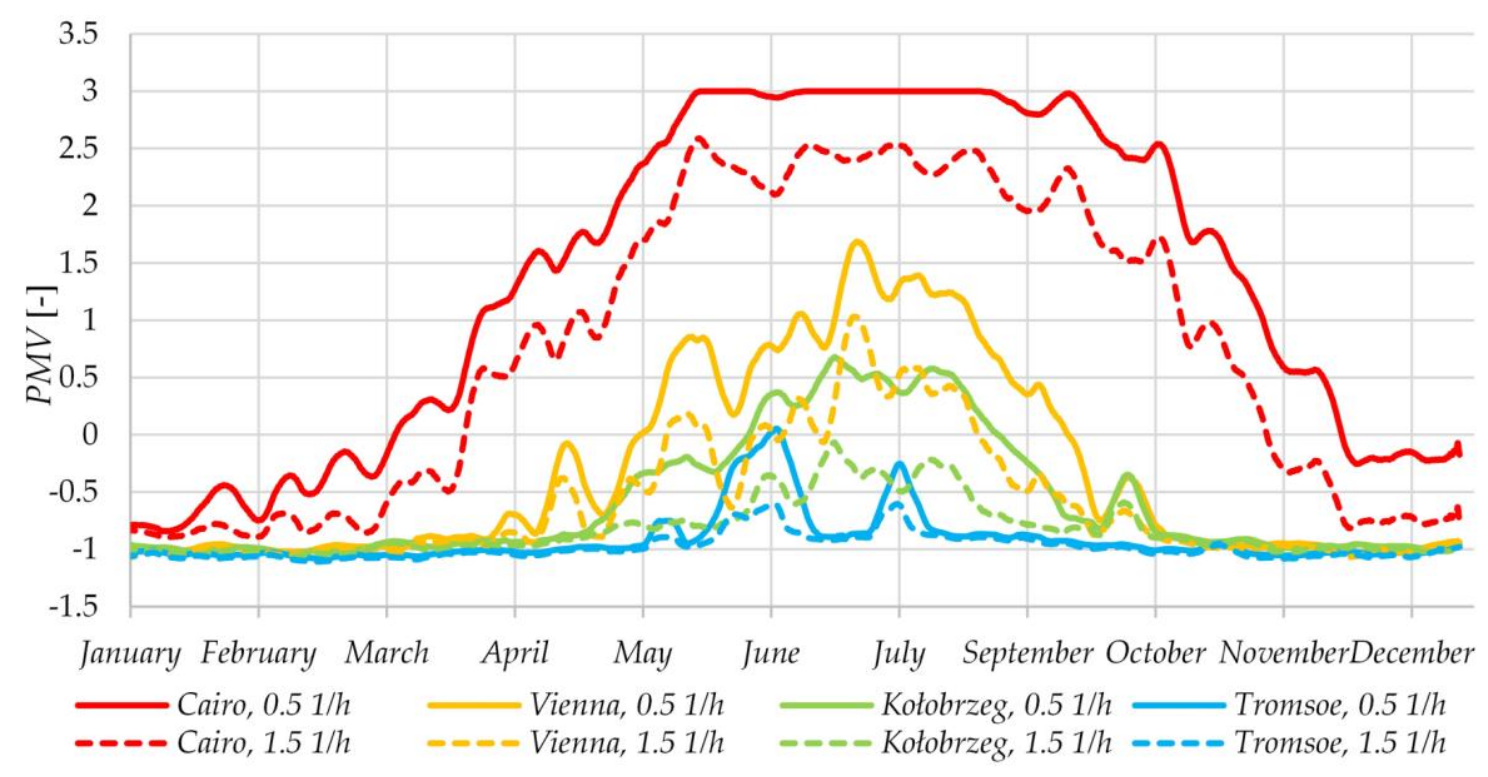

Figure 15. Exemplary PVM diagram for variants based on LWAC500, at different locations, with different levels of ventilation and without a cooling system.

Figure 16 shows the annual $\sum|\mathrm{PMV}|$ values for the variants without a cooling system. In contrast to variants with a cooling system, more favorable values were obtained with thinner walls, with lower thermal conductivity coefficients (LWAC500 and FC500) and in hot and warm locations with low ventilation rates. In Cairo, with ventilation rates of 0.5 and $1.01 / \mathrm{h}$, the differences reached $2-3 \%$ in favor of thinner wall variants. At a level of $1.51 / \mathrm{h}$, the thicker variant of the wall seemed to be slightly more favorable, while in the cold climate of Tromsoe, the differences between the variants were negligible. 
(a) Cairo, Egypt
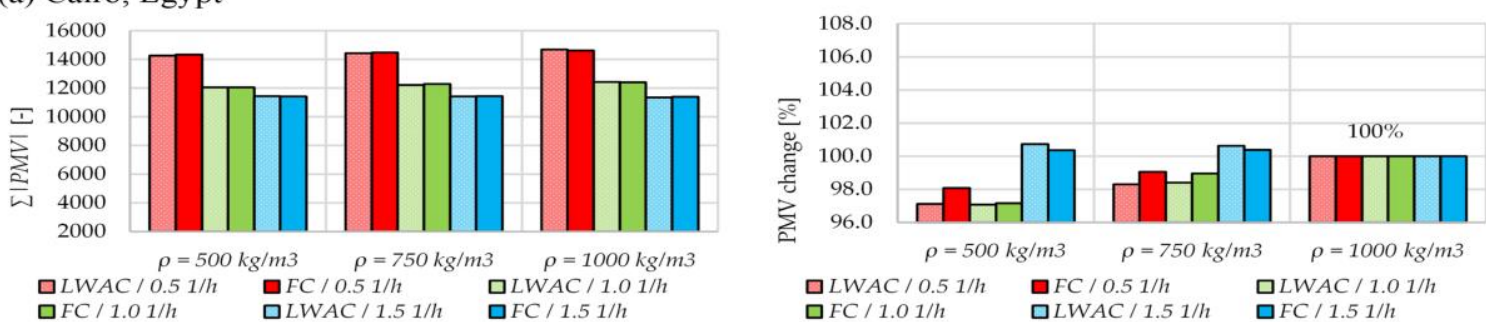

(b) Vienna, Austria
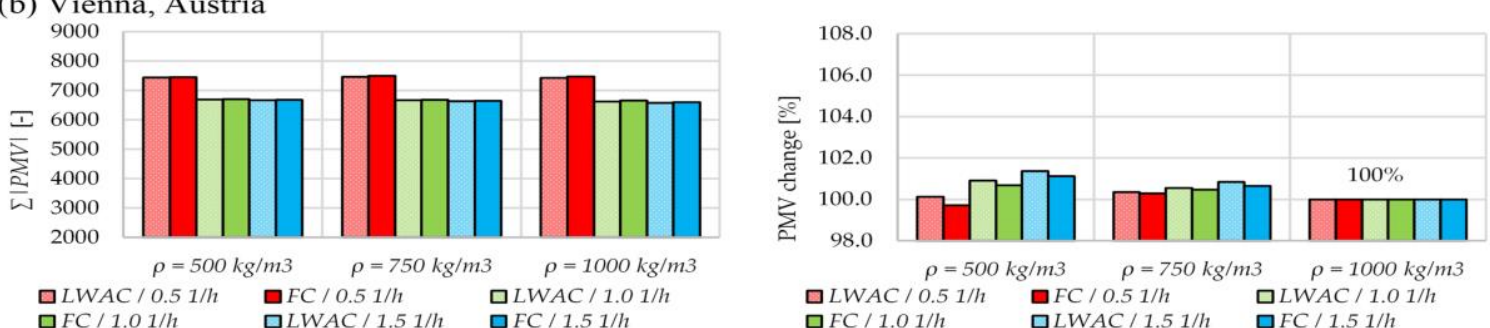

(c) Kołobrzeg, Poland
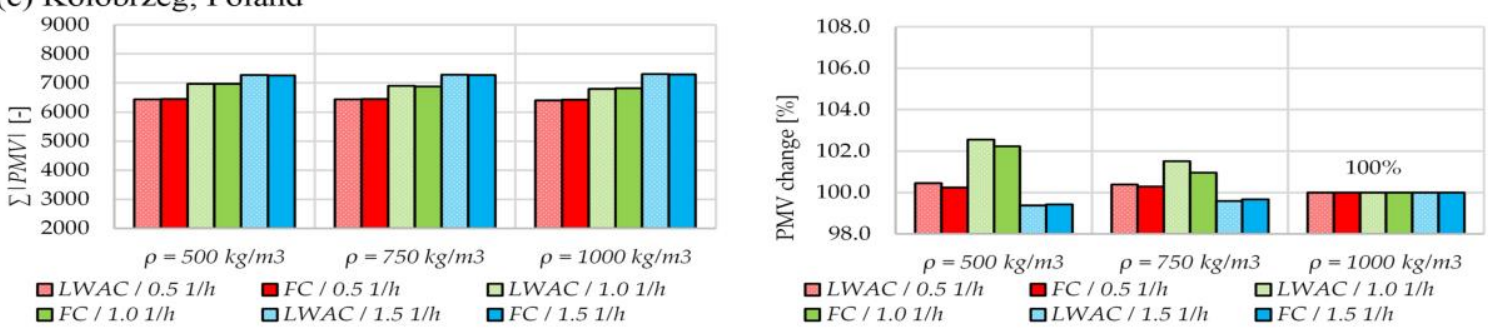

(d) Tromsoe, Norway
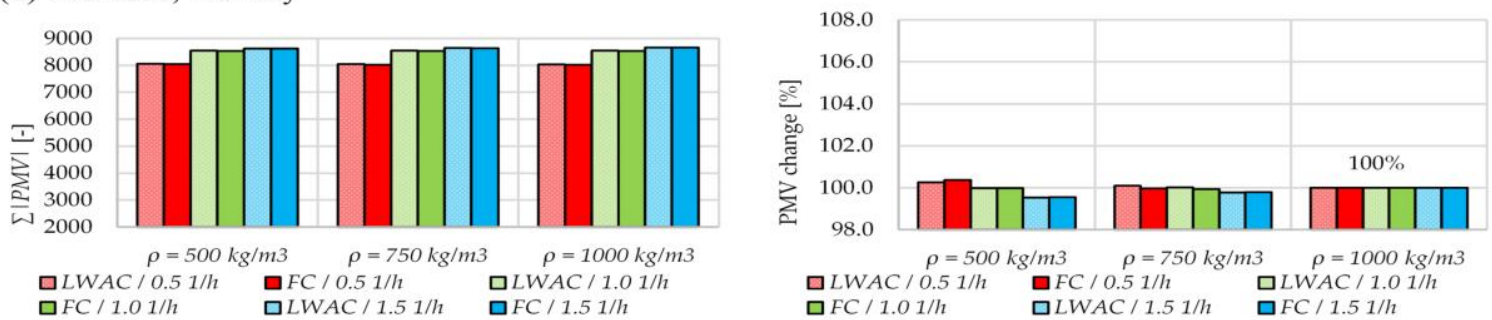

Figure 16. Annual total $|\mathrm{PVM}|$ for building variants without a cooling system.

The exemplary graphs of internal temperature, for variants based on LWAC500, are shown in Figure 17. Results are shown for ventilation levels of 0.5 and $1.51 / \mathrm{h}$ and no cooling system. The horizontal, purple line highlights the parts of the graphs defined as 'overheated'. As expected, increasing the ventilation level rate, significantly lowered the mean indoor temperature. Nevertheless, in warm locations it was insufficient. 


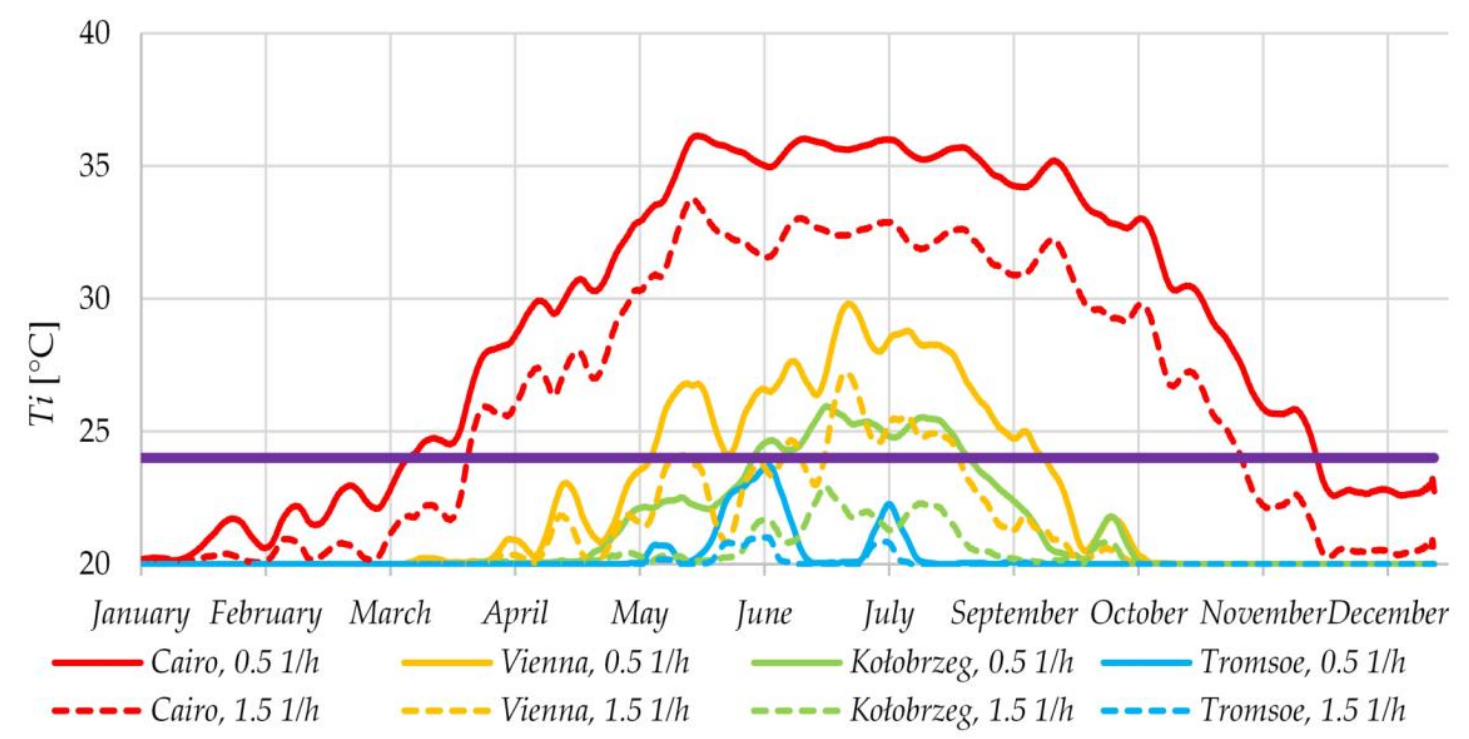

Figure 17. Exemplary internal temperature diagram for variants based on LWAC500, in different locations and with different levels of ventilation, without a cooling system.

For all the variants without a cooling system, the number of hours exceeding an internal temperature above $24^{\circ} \mathrm{C}$ were calculated for the whole year and are presented in Figure 18. Generally, wall materials with a density of $500 \mathrm{~kg} / \mathrm{m}^{3}$ were more favorable in hot climates. The number of hours exceeding the internal temperature was up to $8 \%$ lower with the ventilation set to $0.5 \mathrm{l} / \mathrm{h}$. A similar tendency was observed in the case of Kołobrzeg (ventilation rate of $0.51 / \mathrm{h}$ ). The overheating temperature did not occur with higher ventilation rates in Kołobrzeg, but the situation was more complex in Vienna. Here, in the case of ventilation at levels of 0.5 and $1.01 / \mathrm{h}$, the variants based on materials with a lower density were more favorable. On the other hand, in the case of strong ventilation at a level of $1.51 / \mathrm{h}$, the variant with a $1000 \mathrm{~kg} / \mathrm{m}^{3}$ wall density was more beneficial. In the case of Tromsoe, wall layer material thermal accumulation did not affect the results due to the fact that the internal temperature did not practically exceed $24^{\circ} \mathrm{C}$. In hot and warm climates, differences between different density variants were more favorable when LWACs were used. This was due to their higher volume specific heat, as compared to the FC variants. 
(a) Cairo, Egypt
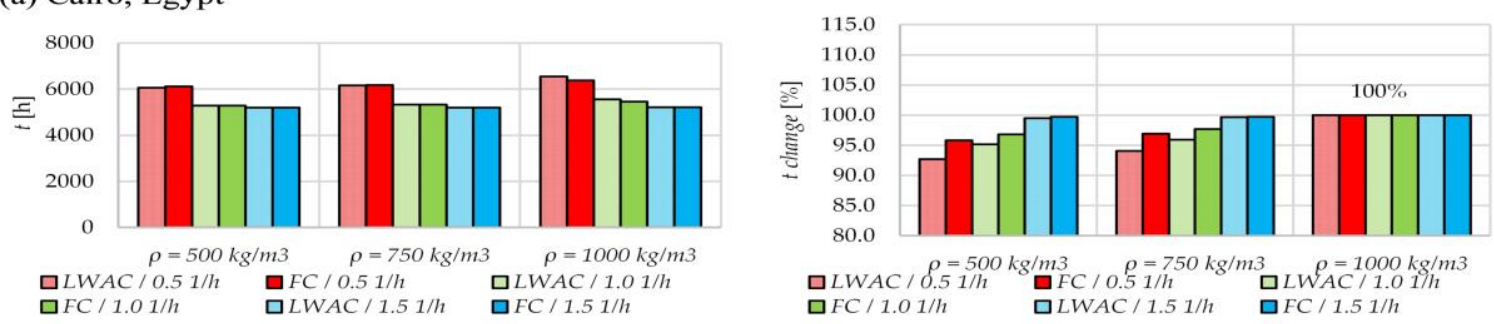

(b) Vienna, Austria
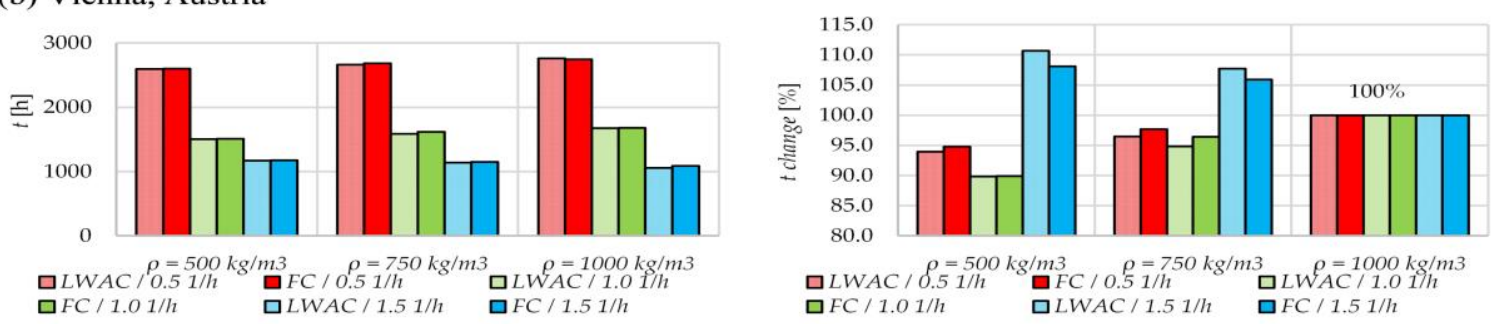

(c) Kołobrzeg, Poland
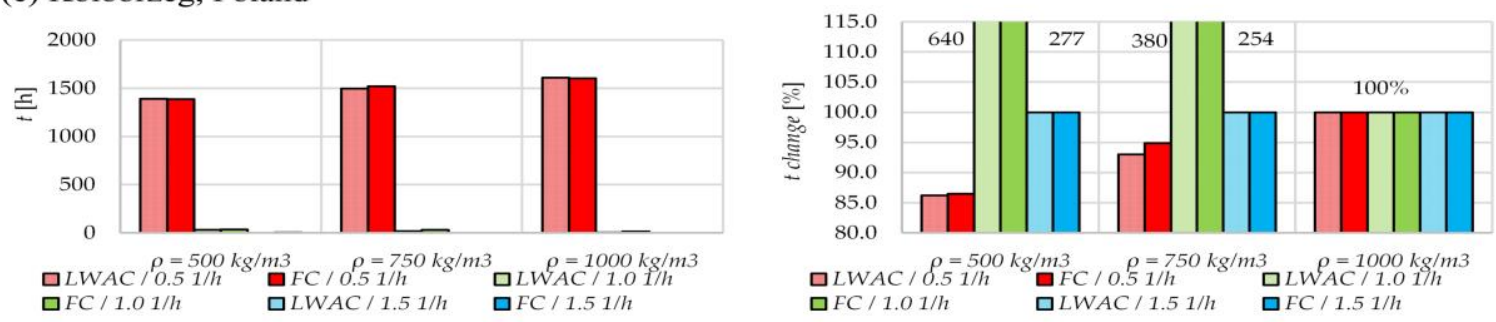

(d) Tromsoe, Norway
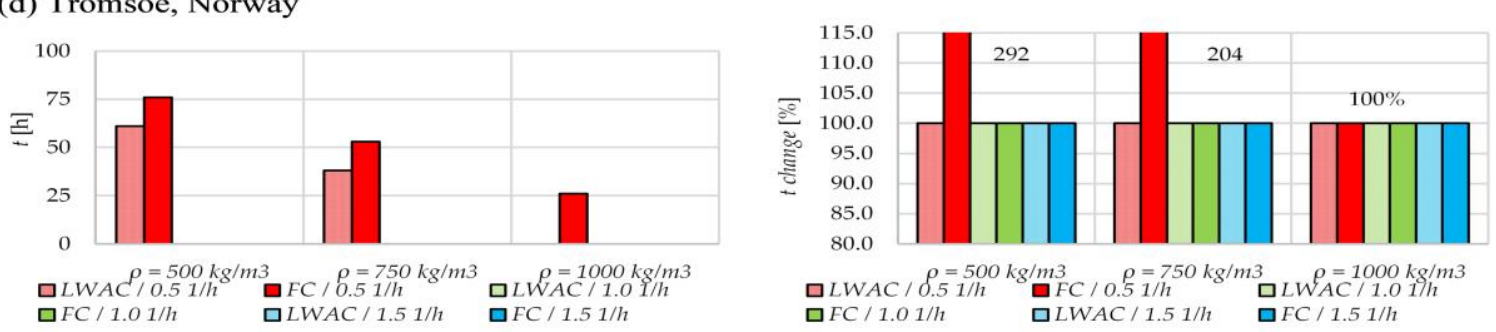

Figure 18. The number of hours exceeding an internal temperature above $24^{\circ} \mathrm{C}$, for building variants without a cooling system. 


\section{Discussion}

When comparing the dynamic thermal characteristics of the particular concrete types tested, it is worth taking note of the effects of the higher volume specific heat values, in the lightweight aggregate concretes, which affected both thermal admittance and internal heat capacity. Slightly higher values for both were achieved in the case of LWAC. LWAC's higher specific heat values also resulted in a significant reduction in periodic thermal transmittance, as compared to FC with the same density. In addition, a reduction in the decrement factor values, in comparison to the corresponding FC variants, was observed.

The differences in the thermal properties of the concretes resulted in some variations in the results between LWAC and FC. The relationships between selected dynamic thermal characteristic parameters and the results of the energy balance of the buildings tested are presented below.

Figure 19 presents the relationship between the total $|\mathrm{PVM}|$ and the internal thermal admittance, of six types of external walls tested, at all four locations with a ventilation rate of $0.51 / \mathrm{h}$. Similar relationships were observed for the other test ventilation rates. Except for Tromsoe, the coefficients of determination obtained had rather high values. In the thermal admittance range tested, the differences were rather small. The greatest decrease in $|\mathrm{PVM}|$, with an increase in thermal admittance, was observed for the hot climate in Cairo (the highest slope of the trendline). 


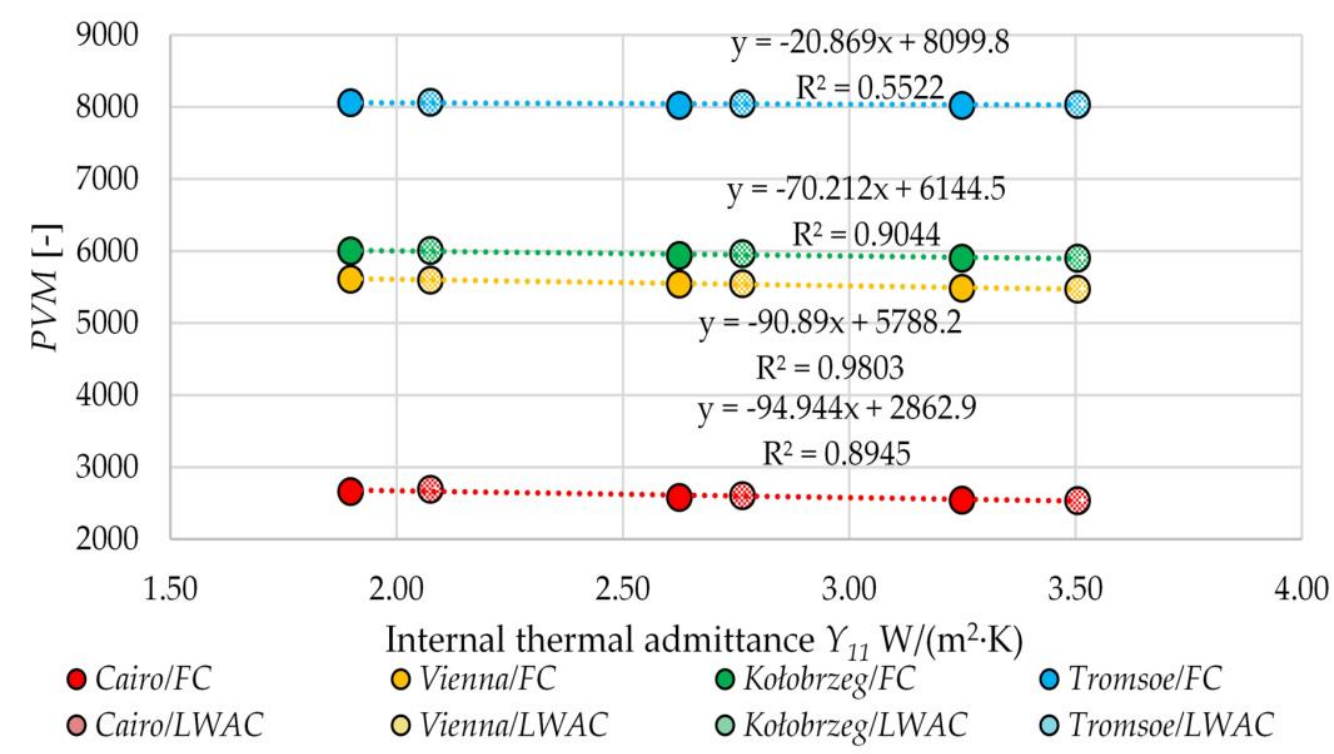

Figure 19. Relationship between total $|\mathrm{PMV}|$ and internal thermal admittance, $Y_{1 l}$, for variants with a ventilation rate $0.51 / \mathrm{h}$ and a cooling system.

The relationships between the maximum hourly heating demand, $Q_{H, n d}$, and the internal areal heat capacity, $K_{l}$, for the variants with a cooling system, at all four locations, are presented in Figure 20. For all the variants tested, high coefficient of determination values was obtained. The maximum heating demand decreased with an increase in internal areal heat capacity. A stronger decrease was observed for variants with a ventilation rate of $1.01 / \mathrm{h}$, for which the slopes of the trend lines were the steepest. 
(a) Cairo, Egypt

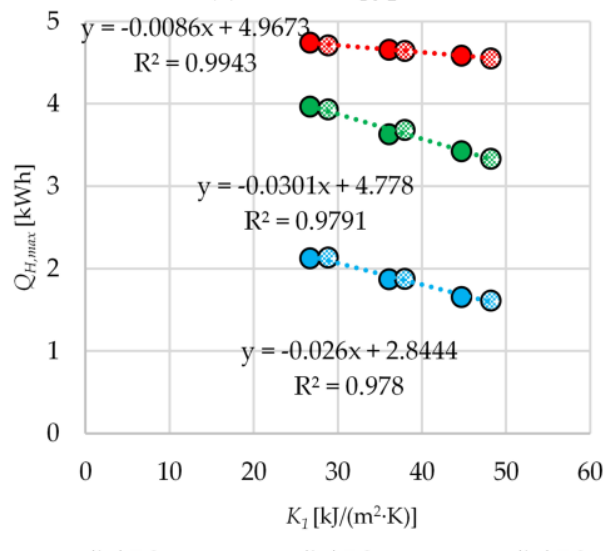

○ $0.51 / h / F C \quad 01.01 / h / F C \quad 01.51 / h / F C$

○ $0.51 / h / L W A C$ o $1.01 / h / L W A C$ o $1.51 / h / L W A C$

(c) Kołobrzeg, Poland

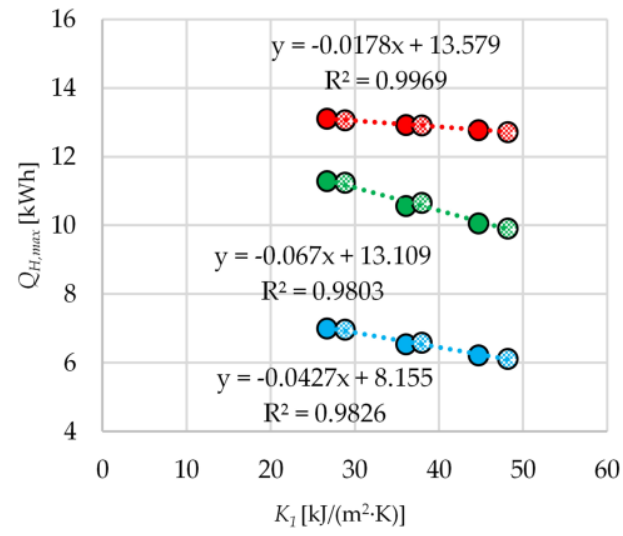

- $0.51 / h / F C \quad 01.01 / h / F C \quad 01.51 / h / F C$

○ $0.51 / h / L W A C$ o $1.01 / h / L W A C$ o $1.51 / h / L W A C$ (b) Vienna, Austria

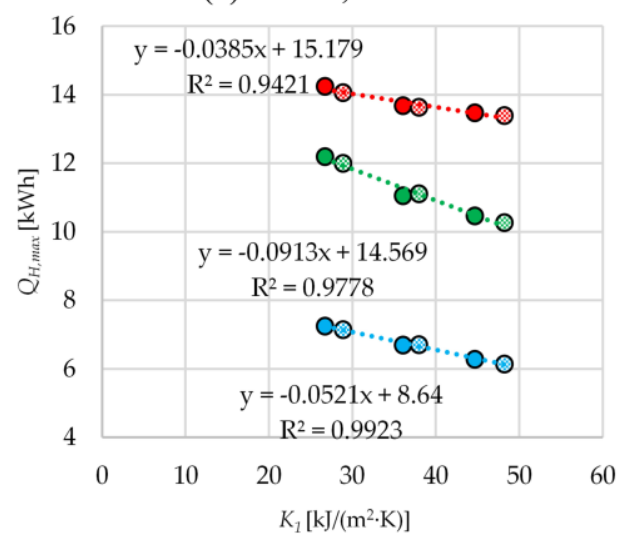

- $0.51 / h / F C \quad 01.01 / h / F C \quad 01.51 / h / F C$

○ $0.51 / h / L W A C$ o $1.01 / \mathrm{h} /$ LWAC 0 $1.51 / \mathrm{h} /$ LWAC

(d) Tromsoe, Norway

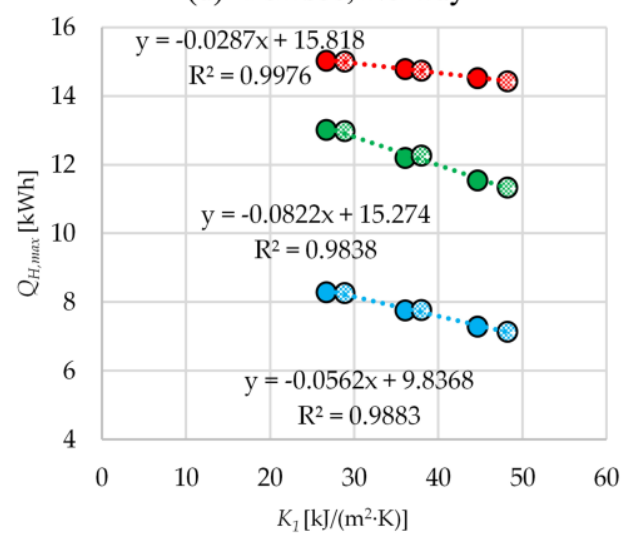

- $0.51 / h / F C \quad 01.01 / h / F C \quad 01.51 / h / F C$

○ $0.51 / h / L W A C$ o $1.01 / h / L W A C$ o $1.51 / h / L W A C$

Figure 20. The relationship between the maximum hourly heating demand, $Q_{H, \max }$, and the internal areal heat capacity, $K_{l}$, for variants with a cooling system.

The relationships between maximum hourly cooling demand, $Q_{C, n d}$, and internal areal heat capacity, are presented in Figure 21. Similarly, to heating demand, the instantaneous cooling demand decreased with an increase in internal areal heat capacity. Again, for almost all the variants, $\mathrm{R}^{2}$ was high and the biggest slope for the trend lines was with a ventilation rate of $1.0 \mathrm{1} / \mathrm{h}$. The highest influence of heat capacity was observed for the hot climate of Cairo. The colder the climate, the smaller the effect of heat capacity of cooling demand. 
(a) Cairo, Egypt

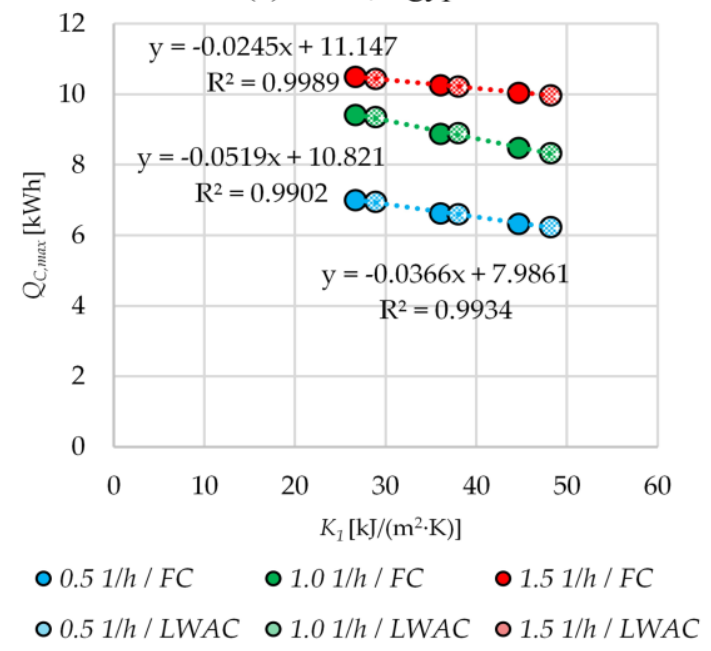

(c) Kołobrzeg, Poland

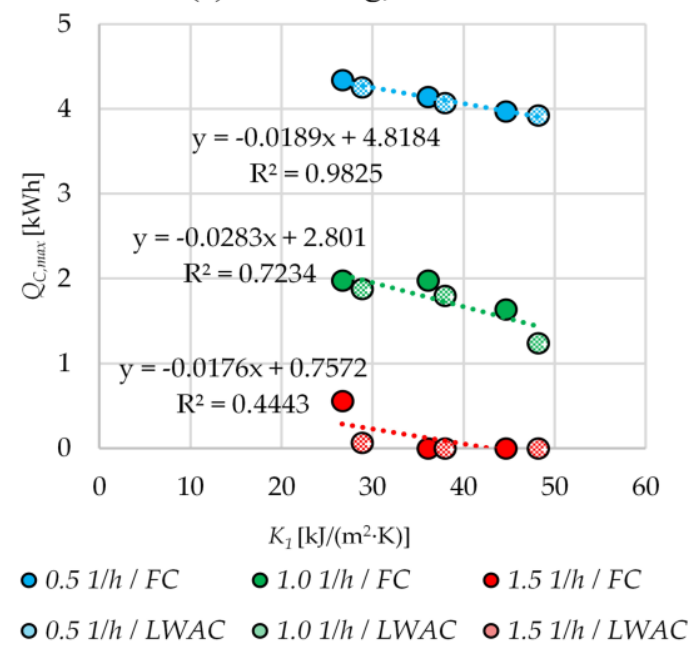

(b) Vienna, Austria

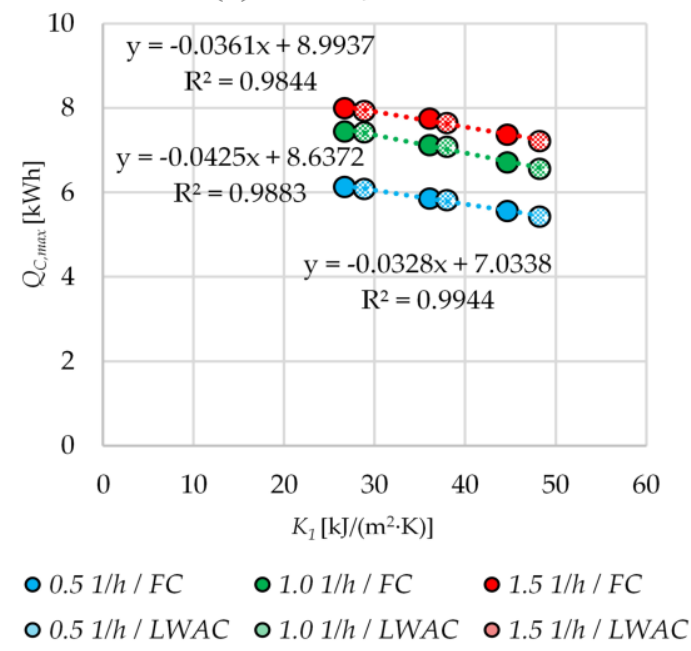

(d) Tromsoe, Norway

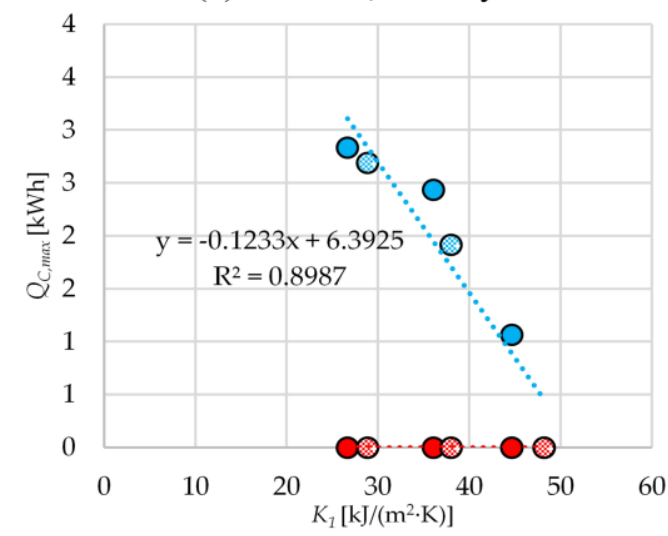

- $0.51 / h / F C \quad 01.01 / h / F C \quad 01.51 / h / F C$

○ $0.51 / h / L W A C$ o $1.01 / h / L W A C$ o $1.51 / h / L W A C$

Figure 21. The relationship between the maximum hourly cooling demand, $Q_{C, \max }$, and the internal areal heat capacity, $K_{l}$, for variants with a cooling system.

The relationship between the number of hours exceeding an internal temperature above $24^{\circ} \mathrm{C}$ and the internal areal heat capacity, for building variants without a cooling system, is shown in Figure 22. This relationship is much more complex. In the case of the hot Cairo climate, an increase in heat capacity resulted in an increase in the number of hours exceeding an internal temperature above $24^{\circ} \mathrm{C}$, with a ventilation rate of 0.5 and $1.01 / \mathrm{h}$. For ventilation of $1.51 / \mathrm{h}$, the line trend was almost horizontal. In the warm Vienna climate, at a ventilation rate of 0.5 and $1.01 / \mathrm{h}$, an increase in heat capacity also increased the number of hours exceeding the internal temperature, although a decrease was observed at the higher ventilation rate $(1.51 / \mathrm{h})$. 
The relationships in colder climates were different. In Kołobrzeg, a small decrease was also observable for the $1.01 / \mathrm{h}$ ventilation rate. In the cold climate of Tromsoe, for the only variant in which temperatures above $24^{\circ} \mathrm{C}$ occurred, the trend was also decreasing.

(a) Cairo, Egypt

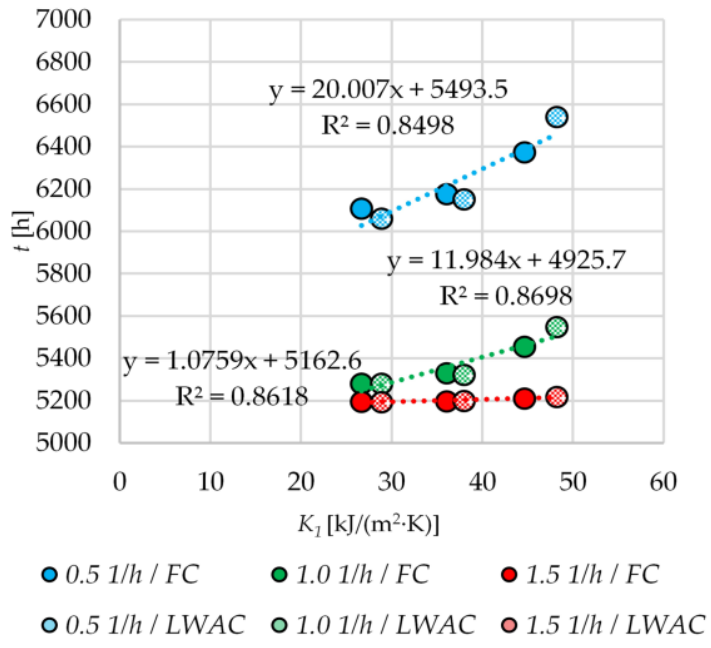

(c) Kołobrzeg, Poland

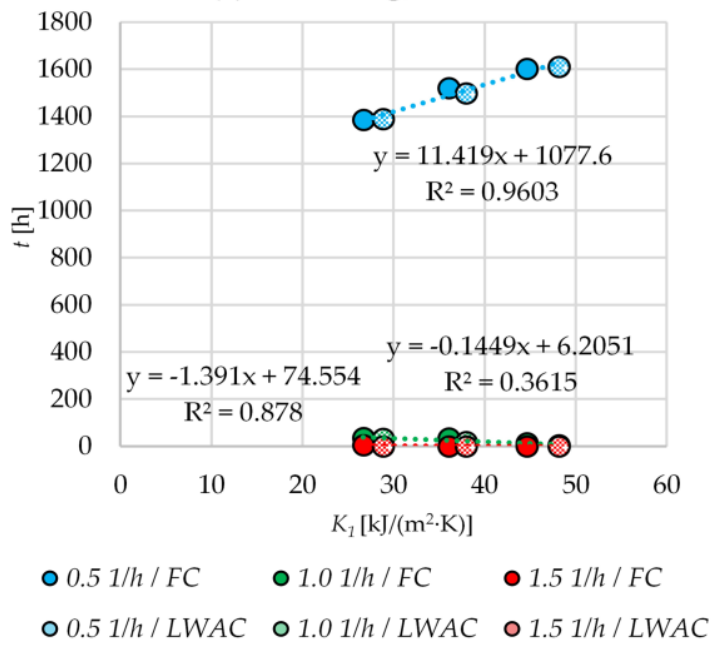

(b) Vienna, Austria

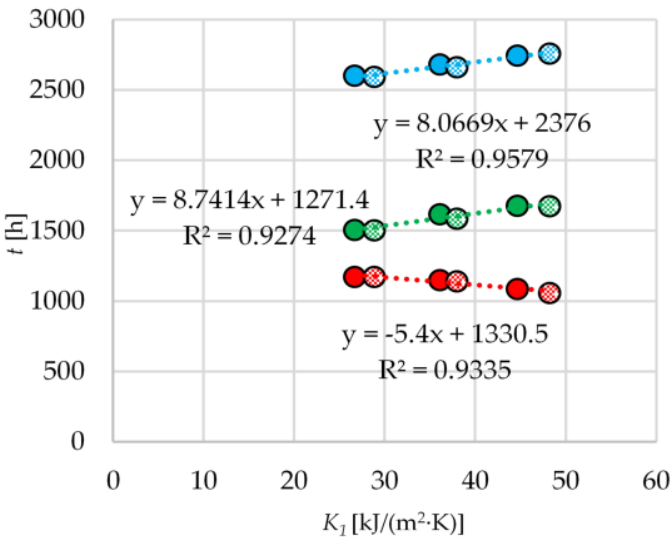

- $0.51 / h / F C \quad 01.01 / h / F C \quad 01.51 / h / F C$

○ $0.51 / h / L W A C$ o $1.01 / h / L W A C$ o $1.51 / h / L W A C$

(d) Tromsoe, Noway

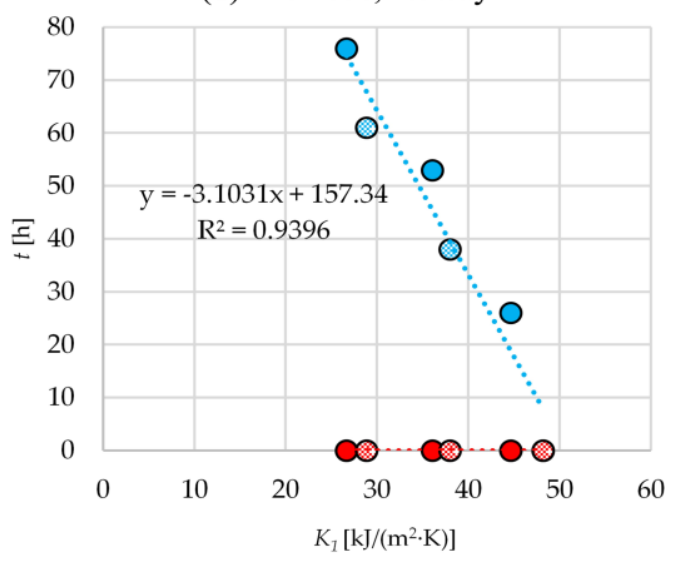

- $0.51 / h / F C \quad 01.01 / h / F C \quad 01.51 / h / F C$

○ $0.51 / h / L W A C$ o $1.01 / h / L W A C$ o $1.51 / h / L W A C$

Figure 22. The relationship between the number of hours exceeding an internal temperature above $24^{\circ} \mathrm{C}$ and the internal areal heat capacity $K_{l}$, for building variants without a cooling system. 


\section{Conclusions}

This study examined the influence of lightweight concretes of different densities, used as external wall layers, on the thermal performance of a typical multi-family building. The concluding remarks of this study can be summarized as follows:

- The use of concrete with higher thermal conductivity and greater thickness makes it possible to obtain an external wall with a much higher internal heat capacity and higher internal thermal admittance. These kinds of walls maintain the same thermal transmittance as walls made from materials of higher thermal insulation and lower thickness. They are also characterized by a much lower periodic thermal transmittance.

- The use of thicker wall layers with higher thermal conductivity reduces the heating demand in cold and moderate climates by 10 to $14 \%$. Such partitions also make it possible to reduce the instantaneous hourly heating demand; from $12-15 \%$ in cold climates, up to $28-32 \%$ in the tested hot Cairo climate.

- Thick external walls also help to reduce hourly peak cooling demand (up to $13 \%$ in mild warm and hot climate). In the case of a hot climate, with the highest cooling demand, the application of walls with a density of $1000 \mathrm{~kg} / \mathrm{m}^{3}$ (FC1000 and LWAC1000) resulted in a reduction in the total cooling demand by between 1 and $3 \%$.

- The influence of wall thickness on the total $|\mathrm{PVM}|$ value, in buildings with a cooling system, was highest in hot climates; by up to $6 \%$ in favor of thick wall layers. In mild climates, the difference was about $2 \%$, while in cold climates it was negligible. In the absence of a cooling system, the differences were small or in favor of walls made of materials with lower thermal conductivity (FC500 and LWAC500).

- In buildings without a cooling system, in hot and mild warm climates, in most cases thinner walls with better thermal insulation (FC500 and LWAC500) reduced the number of hours exceeding internal temperatures above $24^{\circ} \mathrm{C}$ by up to $8 \%$, compared to walls based on LWAC100 and FC1000. 
- Such thicker walls, however, require a significant increment of the structural (load-bearing) layer thickness to achieve the required low value of thermal transmittance, and thus negatively affects the cubature of the building itself.

Despite comparable densities and thermal conductivity values in LWAC and FC, their specific heat and thus dynamic thermal properties were different. In general, when comparing LWAC and FC used as wall layers, some differences in the thermal performance of the whole building were reported, when comparing variants of the same density. This is attributable to their porosity and different constituents, which influence the thermal properties of a given concrete composite, and thus the results of the thermal balance of the building tested.

Prior to incorporating these materials as wall layers, other aspects, including mechanical and durability related properties, should be taken into account in order to fully utilize their potential.

Funding: This project received funding from the European Union's Horizon 2020 research and innovation program, as part of Marie Skłodowska-Curie grant agreement No. 841592.

\section{Acknowledgment:}

The authors would like to thank the German Academy of Exchange Services (DAAD), as well as the Egyptian Science and Technology Development Fund (STDF) through the GE-Seed funding program. 


\section{References}

[1] U. Berardi, C. Sprengard, An overview of and introduction to current researches on super insulating materials for high-performance buildings, Energy and Buildings. 214 (2020) 109890. https://doi.org/10.1016/j.enbuild.2020.109890.

[2] H. Zhang, J. Yang, H. Wu, P. Fu, Y. Liu, W. Yang, Dynamic thermal performance of ultra-light and thermal-insulative aerogel foamed concrete for building energy efficiency, Solar Energy. 204 (2020) 569-576. https://doi.org/10.1016/j.solener.2020.04.092.

[3] Y.S. Vytchikov, I.G. Belyakov, M.Ye. Saparev, The Analysis of Heat-and-moisture Conditions of Using Double-Layer Wall Panels, Procedia Engineering. 111 (2015) 853-857. https://doi.org/10.1016/j.proeng.2015.07.158.

[4] M. Kameni Nematchoua, P. Ricciardi, S. Reiter, A. Yvon, A comparative study on optimum insulation thickness of walls and energy savings in equatorial and tropical climate, International Journal of Sustainable Built Environment. 6 (2017) 170-182. https://doi.org/10.1016/j.ijsbe.2017.02.001.

[5] A. Mousa, M. Mahgoub, M. Hussein, Lightweight concrete in America: presence and challenges, Sustainable Production and Consumption. $15 \quad$ (2018) 131-144. https://doi.org/10.1016/j.spc.2018.06.007.

[6] R. Ponechal, D. Staffenova, Impact of external wall insulation thickness on internal surface temperature behaviour, MATEC Web Conf. 117 (2017) 00140. https://doi.org/10.1051/matecconf/201711700140.

[7] P. Sikora, T. Rucinska, D. Stephan, S.-Y. Chung, M. Abd Elrahman, Evaluating the effects of nanosilica on the material properties of lightweight and ultra-lightweight concrete using imagebased approaches, Construction and Building Materials. $264 \quad$ (2020) 120241. https://doi.org/10.1016/j.conbuildmat.2020.120241.

[8] M. Elshahawi, A. Hückler, M. Schlaich, Infra lightweight concrete: A decade of investigation (a review), Structural Concrete. n/a (n.d.). https://doi.org/10.1002/suco.202000206.

[9] Y.H. Pan, K.W. Wong, C.M. Hui, Cost Comparison between the Construction of Lightweight and Conventional Partitions in Chongqing, China, International Journal of Construction Management. 7 (2007) 57-70. https://doi.org/10.1080/15623599.2007.10773095.

[10] D. Kumar, P.X.W. Zou, R.A. Memon, M.M. Alam, J.G. Sanjayan, S. Kumar, Life-cycle cost analysis of building wall and insulation materials, Journal of Building Physics. 43 (2020) 428 455. https://doi.org/10.1177/1744259119857749.

[11] Z. Che Muda, P. Shafigh, N. Binti Mahyuddin, S.M.E. Sepasgozar, S. Beddu, A. Zakaria, Energy Performance of a High-Rise Residential Building Using Fibre-Reinforced Structural Lightweight Aggregate Concrete, Applied Sciences. 10 (2020) 4489. https://doi.org/10.3390/app10134489. 
[12] S. Liu, K. Zhu, S. Cui, X. Shen, G. Tan, A novel building material with low thermal conductivity: Rapid synthesis of foam concrete reinforced silica aerogel and energy performance simulation, Energy and Buildings. 177 (2018) 385-393. https://doi.org/10.1016/j.enbuild.2018.08.014.

[13] K.-C. Thienel, T. Haller, N. Beuntner, Lightweight Concrete-From Basics to Innovations, Materials. 13 (2020) 1120. https://doi.org/10.3390/ma13051120.

[14] J. Strzallkowski, H. Garbalińska, Thermal simulation of building performance with different loadbearing materials, IOP Conf. Ser.: Mater. Sci. Eng. 415 (2018) 012014. https://doi.org/10.1088/1757-899X/415/1/012014.

[15] F. Roberz, R.C.G.M. Loonen, P. Hoes, J.L.M. Hensen, Ultra-lightweight concrete: Energy and comfort performance evaluation in relation to buildings with low and high thermal mass, Energy and Buildings. 138 (2017) 432-442. https://doi.org/10.1016/j.enbuild.2016.12.049.

[16] M. Robati, G. Kokogiannakis, T.J. McCarthy, Impact of structural design solutions on the energy and thermal performance of an Australian office building, Building and Environment. 124 (2017) 258-282. https://doi.org/10.1016/j.buildenv.2017.08.018.

[17] S.-Y. Chung, M. Abd Elrahman, J.-S. Kim, T.-S. Han, D. Stephan, P. Sikora, Comparison of lightweight aggregate and foamed concrete with the same density level using image-based characterizations, Construction and Building Materials. 211 (2019) 988-999. https://doi.org/10.1016/j.conbuildmat.2019.03.270.

[18] ISO 22007-2:2015 Plastics — Determination of thermal conductivity and thermal diffusivity Part 2: Transient plane heat source (hot disc) method.

[19] Competitive landscape of the EU's insulation materials industry for energy-efficient buildings, EU Science Hub - European Commission. (2018). https://ec.europa.eu/jrc/en/publication/competitive-landscape-eu-s-insulation-materials-industryenergy-efficient-buildings (accessed November 7, 2020).

[20] U-values for better energy performance of buildings, Energy - European Commission. (2016). https://ec.europa.eu/energy/content/u-value-building-element_en (accessed November 7, 2020).

[21] H.M. Künzel, H.M. Künzel, K. Sedlbauer, A. Holm, et al, Entwicklung der hygrothermischen Simulation im Bauwesen am Beispiel der Softwarefamilie WUFI ${ }^{\circledR}$, Wksb. Zeitschrift Für Wärmeschutz, Kälteschutz, Schallschutz, Brandschutz. 51 (2006) 7-14.

[22] T. Schöpfer, F. Antretter, C. van Treeck, et al, Validierung energetischer Gebäudesimulationsmodelle mit der VDI 6020, in: BauSIM 2010. Building Performance Simulation in a Changing Environment, 2010: pp. 529-534.

[23] ISO 13786:2017 Thermal performance of building components - Dynamic thermal characteristics - Calculation methods. 